\title{
Enhanced properties of chitosan microparticles over bulk chitosan on the modulation of auxin signaling pathway with beneficial impacts on root architecture in plants
}

Maria Jose Iglesias, Silvana L Colman, Maria Cecilia Terrile, Ramiro Paris, Sergio MartínSaldaña, Alberto Antonio Chevalier, Vera Alejandra Alvarez, and Claudia Casalongue

J. Agric. Food Chem., Just Accepted Manuscript • DOI: 10.1021/acs.jafc.9b00907 • Publication Date (Web): 03 Jun 2019

Downloaded from http://pubs.acs.org on June 7, 2019

\section{Just Accepted}

"Just Accepted" manuscripts have been peer-reviewed and accepted for publication. They are posted online prior to technical editing, formatting for publication and author proofing. The American Chemical Society provides "Just Accepted" as a service to the research community to expedite the dissemination of scientific material as soon as possible after acceptance. "Just Accepted" manuscripts appear in full in PDF format accompanied by an HTML abstract. "Just Accepted" manuscripts have been fully peer reviewed, but should not be considered the official version of record. They are citable by the Digital Object Identifier (DOI®). "Just Accepted" is an optional service offered to authors. Therefore, the "Just Accepted" Web site may not include all articles that will be published in the journal. After a manuscript is technically edited and formatted, it will be removed from the "Just Accepted" Web site and published as an ASAP article. Note that technical editing may introduce minor changes to the manuscript text and/or graphics which could affect content, and all legal disclaimers and ethical guidelines that apply to the journal pertain. ACS cannot be held responsible for errors or consequences arising from the use of information contained in these "Just Accepted" manuscripts. 
Enhanced properties of chitosan microparticles over bulk chitosan on the modulation of auxin signaling pathway with beneficial impacts on root architecture in plants

María José Iglesias ${ }^{1}$, Silvana Lorena Colman ${ }^{1}$, María Cecilia Terrile ${ }^{1}$, Ramiro París ${ }^{1}$, Sergio Martín-Saldaña², Alberto Antonio Chevalier ${ }^{2}$, Vera Alejandra Álvarez ${ }^{3}$ and Claudia Anahí Casalongué1*

${ }^{1}$ UNMdP,CONICET-, Instituto de Investigaciones Biológicas, UE-CONICET-UNMdP, Facultad de Ciencias Exactas y Naturales, Universidad Nacional de Mar del Plata. Funes 3250, B7600, Mar del Plata, Argentina

${ }^{2}$ Gihon Laboratorios Químicos SRL, Calle 4 y 5 Parque Industrial Gral. Salvio, B7600, Mar del Plata, Argentina

3UNMdP, CONICET, Instituto Investigación de Ciencia \& Tecnología de Materiales INTEMA, UE-CONICET-UNMDP, Grupo Materiales Compuestos Termoplásticos, Facultad de Ingeniería, Universidad Nacional de Mar del Plata. Av. Colón 10850, B7600, Mar del Plata, Argentina.

*Corresponding author: Casalongué CA: casalong@mdp.edu.ar; telephone +54223753030 ; fax: +542234753030 
1

2

\section{ABSTRACT}

Improving the root system architecture (RSA) under adverse environmental conditions by using biostimulants is emerging as a new trait to boost crop productivity. Recently, we have reported the characterization of novel chitosan-based microparticles (CSMPs) with promising biological properties as rooting agent in lettuce. In this work, we demonstrated that in contrast to bulk chitosan (CS) which exerts root growth inhibition, CS-MPs promoted root growth and development from 1 to $10 \mu \mathrm{g} . \mathrm{ml}^{-1}$ without cytotoxicity effects at higher doses in Arabidopsis and lettuce seedlings. In addition, we studied the mechanistic mode of action of CS-MPs in the development of early RSA in the Arabidopsis model. CS-MPs unchained an accurate and sustained spatio-temporal activation of the nuclear auxin signaling pathway. Our findings validated a promising scenario for the application of CS-MPs in the modulation of RSA to respond to changing soil environment and improved crop performance.

Key words: Arabidopsis, auxin, chitosan microparticles, lettuce, root system architecture.

\section{INTRODUCTION}

The root system architecture (RSA) involves the coordinated growth and development of primary root (PR), lateral root (LR) and adventitious roots in order to improve soil exploration and resource acquisition, being pivotal for plant fitness and crop productivity. ${ }^{1}$ Since the development of RSA is a crucial factor in determining plant survival particularly under adverse environmental conditions, its modulation is emerging as a strategy to generate improvement in crop yields..$^{2,3}$ In this context, the development of new bioactive materials with emerging properties fits with the actual challenge of augmenting crop productivity with reduced environment impact. ${ }^{4,5}$ Chitosan (CS) are composed by $\beta-1,4$-linked glucosamine and $\mathrm{N}$-acetyl glucosamine residues and are generated by the partial deacetylation of chitin polymer. Due to its 
unique properties such as biodegradability, biocompatibility, ubiquity and low cost, CS has several applications in several fields including agriculture. ${ }^{6,7} \mathrm{CS}$ action in the protection of plants against biotic stress by inhibiting microorganism growth and eliciting plant innate immunity has been extensively studied in multiple species. ${ }^{8-10}$ Although CS has been suggested as biostimulant promoting plant growth in several horticultural plants, a delicate unbalance from optimal concentrations leads to growth inhibition with high impact on root development. ${ }^{11,12}$

The patterns of plant development are consolidated by the action of hormonal regulation mechanisms. The dynamic and versatile modulation of auxin biosynthesis, transport and signaling has been found to be required for RSA development under changing environmental conditions. ${ }^{13,14}$ Auxin regulates root development mainly through the nuclear signaling pathway mediated by the TIR1/AFBs receptors. ${ }^{15}$ Auxin binding to TIR1/AFBs receptors triggers the degradation of Aux/IAAs repressors with the consequent activation of auxin response genes. ${ }^{16}$ The early response genes involved Aux/IAAs, SAUR and GH3 gene families. ${ }^{17}$ The inhibition of auxin-induced growth and the repression of auxin gene expression required for root development has been evidenced in CS-treated wheat coleoptiles and sweet orange plants, respectively. ${ }^{18,19}$ Recently, Lopez-Moya, et al. reported the inhibition of PR and LR development in barley and tomato plants. ${ }^{20}$ The same authores demonstrated that CS modulates RSA in Arabidopsis plants through the reppresion of the transcription factor WUSCHEL RELATED HOMEOBOX 5 (WOX5) which is a major regulator gene of root stem cell activity. WOX5 repression was associated to alterations in auxin biosynthesis and transport leading to an over accumulation of auxin in the root tip with detrimental impact on root development, suggesting that doses, frequency and formulation of CS should be adjusted to prevent negative effects on plant development.

Another point to take into account for the application of CS in the field is its limited solubility in water. The complex behavior of bulk CS on plant physiology as a 
consequence of chemically heterogeneous copolymers preparations has slowed down its promissory potential use in agriculture. ${ }^{21,22}$ Therefore, the development of CS particulated systems is an emerging alternative to the complex problems of bulk CS. They are easy to obtain, and also to modify their water solubility and interactive biological ability. ${ }^{23}$ Nevertheless, it is necessary to demonstrate how type, concentration and particle size impact in organs and tissues of plants. We have previously reported the characterization of CS-MPs developed with high molecular weight CS obtained from Pleoticus mulleri fishing industry waste from Argentine Sea (Scheme 1). Preliminary assays have shown that CS-MPs stimulate PR elongation in lettuce seedlings suggesting a novelty potential use as rooting agents. ${ }^{24}$ In this work we studied CS-MPs properties as biostimulant of root development compared to bulk CS and the hormonal mechanism by which CS-MPs impact on the modulation of RSA in Arabidopsis. Arabidopsis is suggested as an adequate model for dicot plant root research since its root system fits with the typical eudicot root topography. ${ }^{25}$

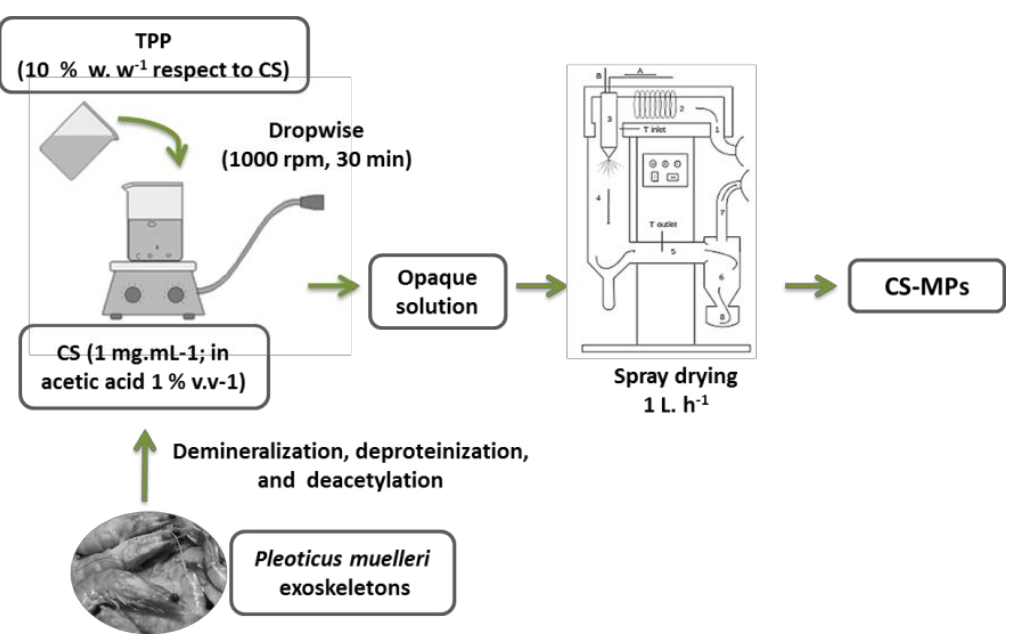

Scheme 1: Synthesis of CS-MPs.

\section{MATERIALS AND METHODS}

\section{Plant materials and growth conditions}

Arabidopsis thaliana (Arabidopsis) wild-type (WT), pMSG2/IAA19:GUS , DR5:GUS, BA3:GUS and DII-VENUS are in the Columbia (Col-0) ecotype. ${ }^{26-29}$ Butterhead lettuce 
(Lactuca sativa L) cv. Reina de Mayo seeds were purchased from "El Colono" local seed market, Mar del Plata, Argentina. Arabidopsis and lettuce seeds were surfacesterilized in $30 \%$ sodium hypochlorite and $0.2 \%$ Tween-20 solution for $10 \mathrm{~min}$, followed by 3 washing steps in sterilized distilled water and stratified at $4{ }^{\circ} \mathrm{C}$ for $2-3 \mathrm{~d}$ in the dark. Seeds were placed on half-strength Murashige and Skoog medium ( $1 / 2 \mathrm{MS})$ (SIGMA-Aldrich, USA) plus $0.8 \%$ agar in Petri plates and grown vertically at $23{ }^{\circ} \mathrm{C}$ under $250 \mu \mathrm{mol}$ photons $\mathrm{m}^{-2} \mathrm{~s}^{-1}$ with 16:8 $\mathrm{h}$ light:dark cycles until analysis.

\section{Chitosan-based materials and treatments}

CS-MPs and CS used in this study were described and characterized by MartínSaldaña, et al. ${ }^{24} \mathrm{CS}$ exhibited a Mass average molecular weight (Mw) of $1531 \pm 372$ $\mathrm{kDa}$, a number average molecular weight $(\mathrm{Mn})$ of $559 \pm 95 \mathrm{kDa}$, a polydispersity index $(\mathrm{Pl}=\mathrm{Mw} / \mathrm{Mn})$ of $1.95 \pm 0.32$ determined by gel permeation chromatography and a deacetylation degree (DD) higher than $87 \%$ determined by Fourier-transform infrared (FTIR) spectroscopy. ${ }^{30}$ CS-MPs were prepared by the gelation method with modifications using sodium tripolyphosphate (TPP) as crosslinker and have a mean diameter of $2.10 \pm 0.78 \mu \mathrm{m}$ and a PDI of 0.14 determined by scanning electron microscopy (SEM;JEOL JSM-6100) with $15 \mathrm{kV}$. Samples were previously coated with metallic gold for $30 \mathrm{~s}$ with an Auto Sputter Coater 108 (Cressington, England). Micrographs were analyzed with ImageJ software (USA National Institutes of Health, (http://rsb.info.nih.gov/ij/)). ${ }^{24,31}$ CS-MP also present a zeta potential value (ろ) of $27.65 \pm$ $1.22 \mathrm{mV}$ at $\mathrm{pH} 6.8$ determined by a laser particle sizer (Z-sizer $3000 \mathrm{HS}$, Malvern, UK) . Materials were developed and characterized by Gihon Laboratorios Químicos SRL, Argentina. Figure $\mathrm{S} 1 \mathrm{a}$ and $\mathrm{b}$ show the morphology of CS-MP by SEM and FTIR spectra and relevant peaks assigned to CS-MP and bulk CS, respectively. FTIR was performed on an IRAffinity-1S FTIR spectrophotometer (Shimadzu, Japan) in the attenuated total reflection mode (ATR-FTIR). To analyze the efficacy of CS-MPs on root growth parameters, the dry CS-MPs were resuspended in water from 0.1 to $100 \mu \mathrm{g}$ 
$\mathrm{mL}^{-1}$. Bulk CS was diluted in $0.1 \%$ acetic acid. The $\mathrm{pH}$ of each assayed dilution of both

112 bulk CS and CS-MP was in the range of 6.0-6.5.

\section{Fresh weight, primary root and lateral root measurements}

114 Five days post-germination (dpg) Arabidopsis and lettuce seedlings were transferred to $1 / 2$ MS medium supplemented with CS-MPS or CS and grown vertically in a growth chamber at $25{ }^{\circ} \mathrm{C}$ under $250 \mu \mathrm{mol}$ photons $\mathrm{m}^{-2} \mathrm{~s}^{-1}$ with $16: 8 \mathrm{~h}$ light:dark cycles until analysis. Root and aerial Fresh weights (FWs) were weighed on a laboratory scale (Sartorius, Germany). Seedlings were photographs after $3 \mathrm{~d}$ for PR length and after $5 \mathrm{~d}$ for LR number and LR length. PR and LR lengths were quantified using the Image J image-analysis software (USA National Institutes of Health, http://rsb.info.nih.gov/ij/).

\section{Measurements of root hair length and density}

Five dpg seedlings were transferred to liquid $1 / 2$ MS medium supplemented with CSMPs or CS for $48 \mathrm{~h}$. Bright-field images from Arabidopsis roots were taken using a Zeiss Axioplan imaging 2 microscope with an Axiocam HRC CCD camera (Zeiss, USA) using the Axiovision program (version 4.2). Root hair $(\mathrm{RH})$ density and length were analyzed in a $5 \mathrm{~mm}$ section from the beginning of the PR differentiation zone. ${ }^{32} \mathrm{RH}$ length was analyzed using Image-analysis software (USA National Institutes of Health, http://rsb.info.nih.gov/ij/).

\section{Root gravitropic assay}

130 Three dpg seedlings were transferred to fresh $1 / 2$ MS medium supplemented with $10 \mu g$ $\mathrm{mL}^{-1}$ CS-MPs. To ensure homogeneous absorption and action, liquid medium was also poured at the surface of each root. The plates were mounted vertically on a scanner (Epson Perfection V600) and let sit for 60 min. After root gravistimulation, images were taken every 15 min for $8 \mathrm{~h}$. Root growth and tip angle were measured by using FIJI software bundle..$^{33}$ \\ Treatment of DII-VENUS transgenic sensor plants with CS-MPs}

DII-VENUS Arabidopsis transgenic sensor seedlings were designed to map auxin signaling response at a high resolution in plant cells. ${ }^{29}$ Five dpg seedlings were 
139 transferred to fresh plates with the addition of $10 \mu \mathrm{g} \mathrm{mL}^{-1} \mathrm{CS}-\mathrm{MPs}$. Liquid solution of

140 CS-MPs $(200 \mu \mathrm{L})$ was poured at the surface of each root to ensure homogeneous absorption. Seedlings were grown for $24 \mathrm{~h}$. Fluorescence from VENUS protein was detected in root cells using a 20 x objective, a 0.5 numerical aperture; and 470/40$525 / 50 \mathrm{~nm}$ as excitation and detection in a Zeiss Axioplan imaging 2 microscope with an Axiocam HRC CCD camera (Zeiss, USA). Images were analyzed by using FIJI software bundle. ${ }^{33}$

\section{Glucuronidase (GUS) staining}

Five dpg transgenic BA3:GUS, DR5:GUS and pMSG2/IAA19:GUS seedlings were transferred into liquid $1 / 2 \mathrm{MS}$ medium containing 1,10 or $100 \mu \mathrm{gL}^{-1} \mathrm{CS}-\mathrm{MPs}$ and then incubated with mild shaking for $24,48,72$ or $96 \mathrm{~h}$ at $23^{\circ} \mathrm{C}$. For BA3:GUS line, CS-MPs particles were applied together with $100 \mathrm{nM}$ indole acetic acid (IAA) and incubated for 6

h. After treatment, BA3:GUS, DR5:GUS and pMSG2/IAA19:GUS seedlings were fixed in $90 \%$ acetone for $1 \mathrm{~h}$ at $20^{\circ} \mathrm{C}$, washed twice in $50 \mathrm{mM}$ sodium phosphate buffer $\mathrm{pH}$ 7.0 and incubated in staining buffer [50 mM Na phosphate ( $\mathrm{pH} 7.0), 5 \mathrm{mM}$ EDTA, $0.1 \%$ Triton X-100, $5 \mathrm{mM} \mathrm{K}_{4} \mathrm{Fe}(\mathrm{CN})_{6}, 0.5 \mathrm{mM} \mathrm{K}_{3} \mathrm{Fe}(\mathrm{CN})_{6}$ and $1 \mathrm{mg} \mathrm{mL}^{-1} \mathrm{X}$-Gluc (5-bromo-4chloro-3-indolyl-beta-D-glucuronic acid, cyclohexylammonium salt) (Gold Biotechnology, USA)] from $2 \mathrm{~h}$ to overnight at $37^{\circ} \mathrm{C}$. Bright-field images were taken using a Zeiss Axioplan imaging 2 microscope (Zeiss, USA).

Measurement of nitric oxide (NO) production. Five dpg Arabidopsis seedlings were loaded in the dark with $5 \mathrm{mM}$ of the specific NO dye DAF-FM-DA (4-Amino-5Methylamino-2',7'-Difluorofluorescein Diacetate; Calbiochem, USA) in 20 mM HEPES$\mathrm{NaOH}$ Buffer at $\mathrm{pH} 7.5$ for 30 min. After three washes, seedlings were examined by epi-fluorescence by using a Nikon DS-Fi 1 digital camera coupled to a Nikon Eclipse Ti (Nikon, Japan) epifluorescence microscope (excitation 495 nm; emission 515-555 nm).

Five dpg seedlings were transferred to liquid $1 / 2$ MS medium supplemented with increasing concentrations of CS-MPs or $10 \mu \mathrm{g} \mathrm{mL}-1$ CS and $\mathrm{H}_{2} \mathrm{O}$ as controls. After 24 
$167 \mathrm{~h}$, total RNA from Arabidopsis seedlings was extracted using TRIzol reagent 168 (Invitrogen, USA) according to the manufacturer's recommendations. Samples were treated with RQ1 RNase-free DNase (Promega, USA) for DNA contamination removal. For cDNA synthesis, $1 \mu \mathrm{g}$ of total RNA was reverse transcribed by IMPROM II (Thermo Fisher Scientific, USA) using random primers (Biodynamics, Argentine). The expression of a subset of early auxin response genes was analyzed by Real Time 173 (qPCR), using the following primers: IAA5F: 5'-CCGGAGAAAGAACAGTCTCG-3'; IAA5R:

5'-AGCATCCGAACAGAATTTGC-3';

IAA14F: $5^{\prime}-$ GAAGCAGAGGAGGCAATGAG-3'; IAA14R: 5'-CCCATGGTAAAGGAGCTGAA-3'; GH3.5F: 5'-CCATCTCTGAGTTCCTCACAAGC-3'; GH3.5R:

$5^{\prime}-$ TCCTCTTCGATTGTTGGCATTAGC-3";

GH3.17F:5'ACGCAGACACGTCATCAATCCC-3";

GH3.17R:

$5^{\prime}-$ TGCTGTGACGTGGCTTTAGCTC-3'; ACTINF: 5'-GCCATCCAAGCTGTTCTCTC-3'; ACTINR: 5'- GAAACCCTCGTAGATTGGCA-3'. qPCR reactions were conducted in triplicates $\left(95^{\circ} \mathrm{C}\right.$ for $10 \mathrm{~min}$, followed by 40 cycles of $95^{\circ} \mathrm{C}$ for $30 \mathrm{~s}, 60{ }^{\circ} \mathrm{C}$ for $30 \mathrm{~s}$ and $72{ }^{\circ} \mathrm{C}$ for $30 \mathrm{~s}$ ) in a Step One real-time PCR system (Applied Biosystems, USA) using FastStart Universal SYBR Green Master Rox (Roche, Germany) following manufacturer's instructions. Results were normalized to the expression level of the gene actin and expressed as fold-change over controls using the comparative cycle threshold (CT) method. ${ }^{34}$ PCR products were analyzed by melting curve analysis to confirm the presence of a single product.

Statistical Analysis

The values shown in figures are mean values +/- standard error (SE) of at least 3 experiments. The data were subjected to analysis of t-Test or ANOVA with Dunnet post hoc comparisons against control by Graphpad Prism version 5.01 software $\left({ }^{*} p<0.05\right.$ $\left.{ }^{* *} p<0.01{ }^{* * *} p<0.001\right)$. 


\section{CS-MPs modulate root architecture in Arabidopsis and lettuce plants}

196

To deep on the potential action of CS-MPs on RSA, we performed a complete analysis of root growth parameters. PR elongation, LR and RH development were studied in 5 dpg Arabidopsis seedlings transferred to $1 / 2$ MS medium supplemented with $0.1,1,10$ and $100 \mu \mathrm{g} \mathrm{mL}-1$ CS-MPs, or CS as control. After $3 \mathrm{~d}$, seedlings grown in $1 \mu \mathrm{g} \mathrm{mL}^{-1} \mathrm{CS}-$ MPs supplemented medium evidenced the higher and significant increment in PR length compared to untreated seedlings (Figure $1 \mathrm{a}$ ). In contrast to CS which at higher doses (10 and $100 \mu \mathrm{g} \mathrm{mL}^{-1}$ ) severely arrested PR elongation, MP-CSs did not show a detrimental effect on PR length in a wide range of assayed doses (Figures 1a and e). In addition, supplementation of the growing medium with 1 and $10 \mu \mathrm{gL}^{-1} \mathrm{CS}-\mathrm{MPs}$ resulted after 5 days of treatment in a $40 \%$ and $60 \%$ of increment in the number and length of LRs, respectively compared with control (Figures $1 \mathrm{~b}$ and $\mathrm{c}$ ). The promotion of LR development was accompanied by slight reduction in PR elongation (Figure 1e). Again, CS-MPs showed a better performance on LR development compared with bulk CS treatment (Figures $1 \mathrm{~b}$ and $\mathrm{c}$ ). In addition to PR inhibition, seedlings exposed to the highest doses of CS evidenced a reduce number of LR, while no cytotoxicity was detected under CS-MPs treatments at the studied concentrations (Figures $1 \mathrm{~b}$ and e). The reduced cytotoxicity of CS-MPs could be explained by the fact that CS-MPs present a reduce number of exposed $-\mathrm{NH} 3+$ positive charges which modified the interactive ability with cell membranes. ${ }^{35}$

In concordance, the rearrangement of RSA triggered by 1 and $10 \mu \mathrm{g} \mathrm{m} \mathrm{L}^{-1} \mathrm{CS}-\mathrm{MPs}$ resulted in approximately $25 \%$ improvement on root and aerial FW after $9 \mathrm{~d}$ of treatment suggesting a positive effect on plant biomass (Figure 1d). Next, we also analyzed the effect of selected CS-MPs concentrations on RH development (Figure 2). Again, due to its emerging physico-chemical properties, CS-MPs at 1 and $10 \mu \mathrm{mL}^{-1}$ resulted in an increment of Arabidopsis $\mathrm{RH}$ density (Figure 2a), and $\mathrm{RH}$ length (Figure $2 \mathrm{~b})$, while no positive effect was detected under $1 \mu \mathrm{g} \mathrm{mL}^{-1} \mathrm{CS}$ treatment. To analyze if the gravitropism as a key root growth process is affected by CS-MPs, the root tip angle 
was quantified after turning the $3 \mathrm{dpg}$ Arabidopsis seedling 90 degrees as described in París, et al. ${ }^{36}$ However, compared with control, CS-MPs treated seedlings did not show changes in root bending, suggesting that CS-MP has specific cell-tissue action (Figure S2). In addition, CS-MPs also promote root development in lettuce (Figure S3). These findings demonstrate that compared with bulk CS, CS-MPs resulted in an improve material to enhance early root growth in Arabidopsis and lettuce seedlings (Figures 1, 2 and S3).

a

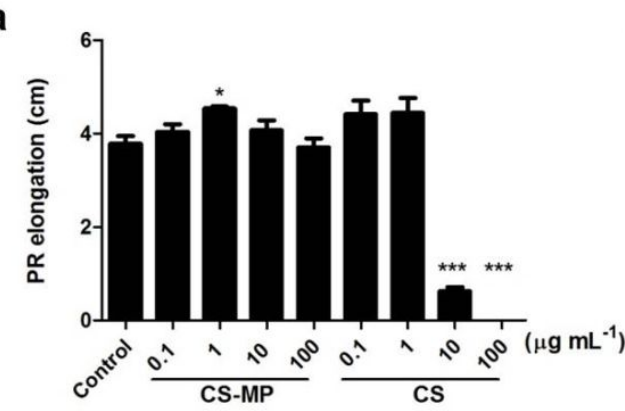

C

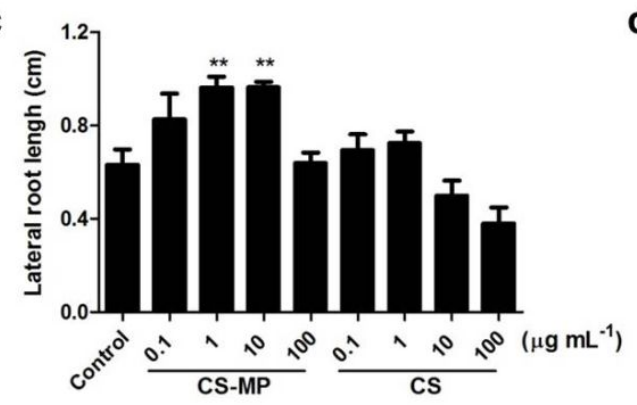

b

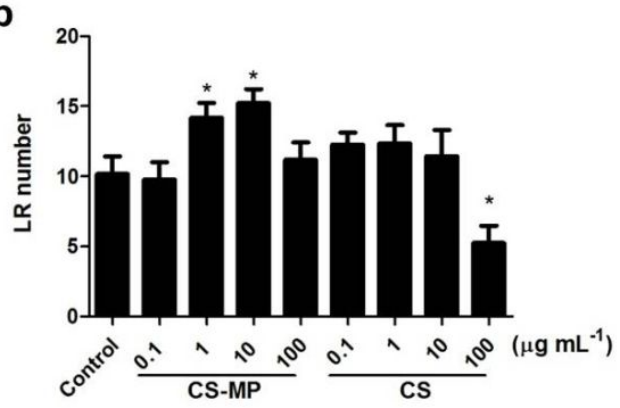

d

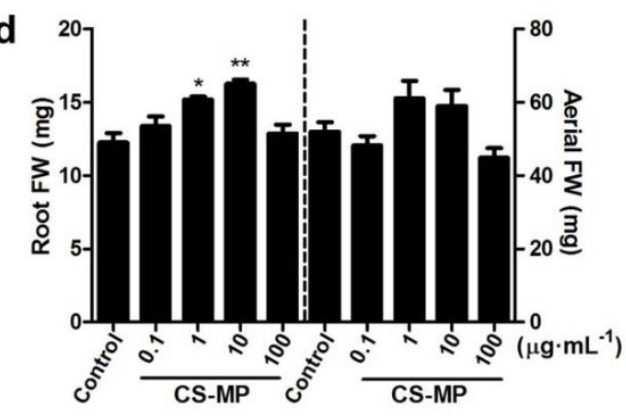

e

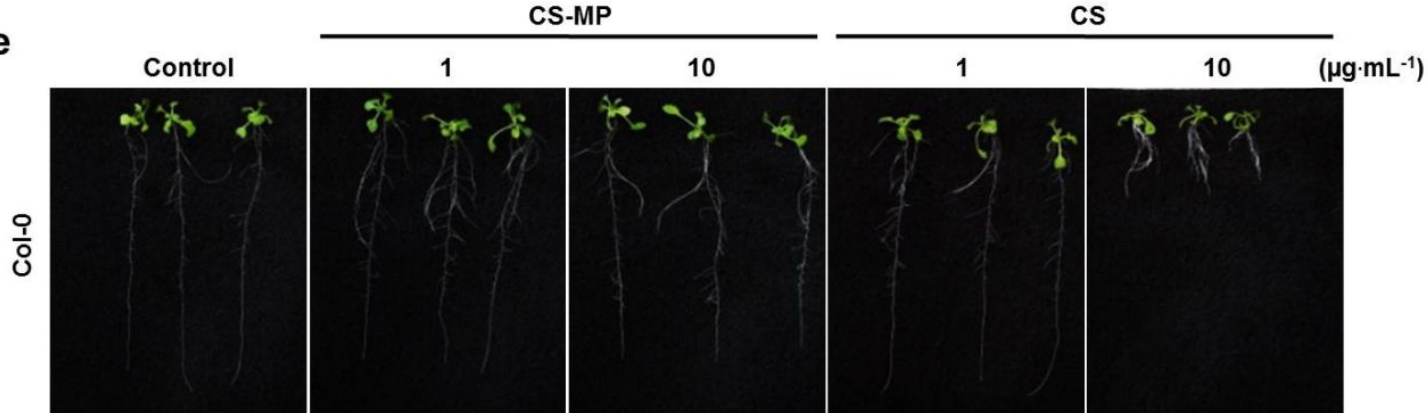

Figure 1. CS-MPs promote root development in Arabidopsis. Five dpg Col-0 Arabidopsis seedlings grown in $1 / 2$ MS medium were treated with increasing concentrations of CS-MPs or CS as control. PR elongation (a) was quantified $3 \mathrm{~d}$ posttreatment. LR number

(b) and LR length

(c) were analyzed $5 \mathrm{~d}$ post treatment. 
236 treatments are shown in (e). Data are mean values of 5 independent experiments $(n=$ 23760 ; ANOVA, Dunnet post-hoc test against control, ${ }^{*} p<0.05^{* *} p<0.01^{* * *} p<0.001$ ).

238

239

240

241

242

243

244

245

246

247

248

249

250

251

252

253

254

255

256

257

258

259

260

261

262

263

264 a

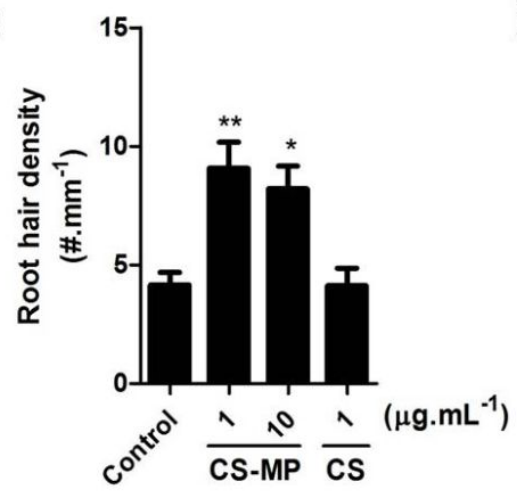

C
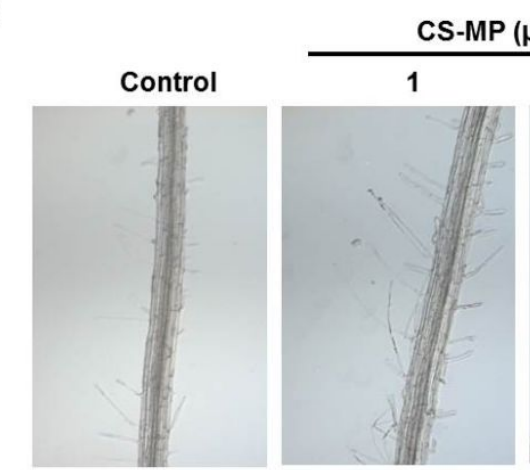

b

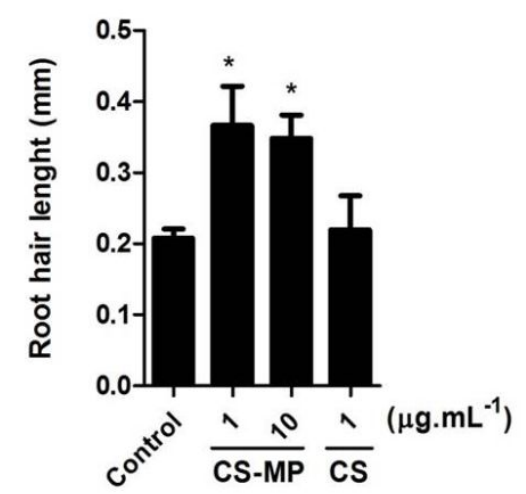

Figure 2. Promotion of RH upon CS-MPs exposure. Five dpg Col-0 Arabidopsis seedlings were transferred to liquid $1 / 2 \mathrm{MS}$ medium supplemented with increasing concentrations of CS-MPS for $48 \mathrm{~h}$. RH density (a) and RH length (b) were analyzed in a $5 \mathrm{~mm}$ section from the beginning of the differentiation zone. Representative images are shown in (c). Data are mean values of 4 independent experiments $(n=30$; ANOVA, Dunnet post-hoc test against control, $\left.{ }^{*} p<0.05\right)$.

\section{Auxin response is activated by CS-MPs in Arabidopsis roots}

Since auxin is a key regulator of root growth and development, we studied if the modulation of auxin signaling constitutes a mechanism of action downstream MP-CSs application in Arabidopsis plants by using the auxin reporter transgenic seedlings, BA3:GUS and DR5:GUS. These lines consist of artificial promoters based on auxin response elements which drive the expression of GUS gene. The activation or repression of auxin response is correlated with GUS activity levels. ${ }^{27,28}$ 


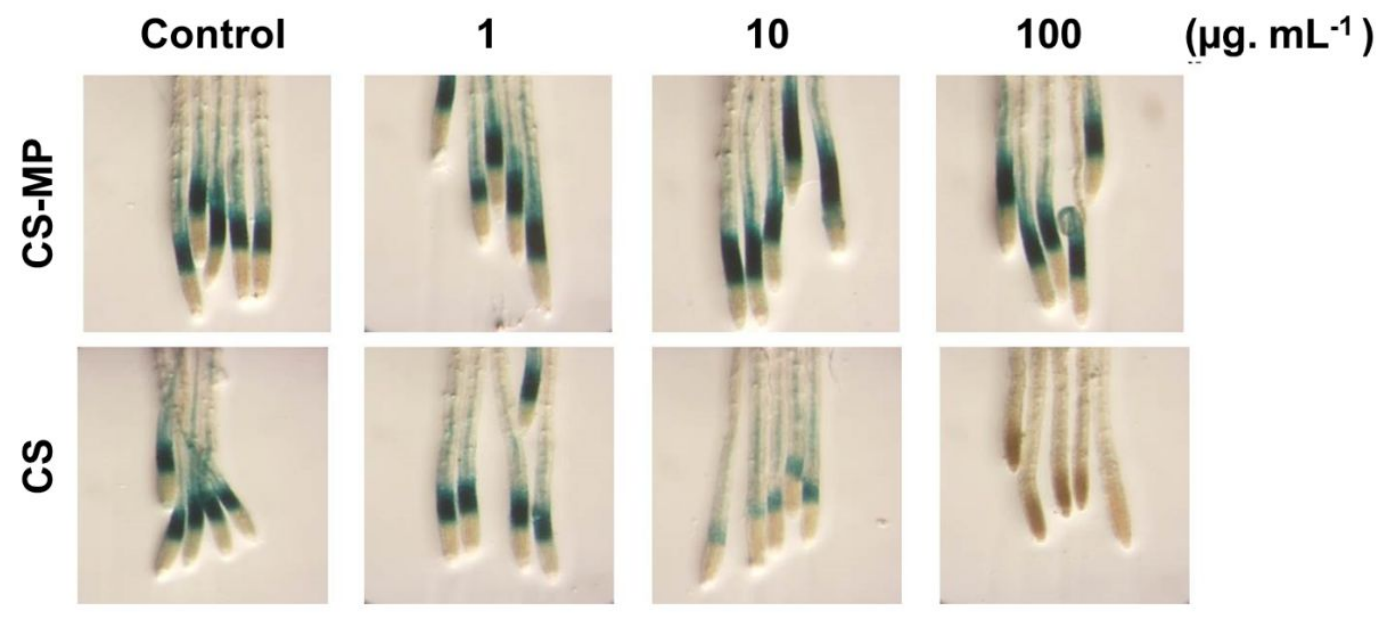

Figure 3. Differential effect of CS-MPs and CS on auxin BA3:GUS reporter gene activity. Five dpg Arabidopsis BA3:GUS seedlings grown in $1 / 2 \mathrm{MS}$ medium were treated with $100 \mathrm{nM}$ IAA and increasing concentrations of CS-MPs or CS. Seedlings were subjected to GUS staining after $5 \mathrm{~h}$ of treatment. Representative images of PR tips are shown.

We studied the effects of CS and CS-MPs on the early activation of auxin response analyzing BA3:GUS activity on the tip of PR of 5-dpg seedlings treated with the natural auxin IAA, in combination with increasing concentrations of CS or CS-MPs for $6 \mathrm{~h}$. While bulk CS repressed BA3 auxin-responsive promoter activity in a dose-dependent manner, CS-MPs did not show an effect on auxin response at all analyzed doses $(0.1$, 1, 10 and $100 \mu \mathrm{g} \mathrm{mL}^{-1}$ ) in an early period of treatment (Figure 3). Repression of auxin response by CS correlated with the cytotoxicity effects on root growth shown in Figure 1e. However, analyzing auxin response after $24 \mathrm{~h}$ of treatment, 1 and $10 \mu \mathrm{gL} \mathrm{m}^{-1} \mathrm{CS}$ MPs triggered the activation of DR5 auxin responsive promoter in the tip of PR of $5 \mathrm{dpg}$ DR5:GUS seedlings (Figures $4 a$ and $b$ ). In concomitance with CS-MPs action on LR (Figure1), an increment in the number of LR primordia showing DR5 activity was detected in 1 and $10 \mu \mathrm{g} \mathrm{mL}-1$ CS-MP treated seedlings after $48 \mathrm{~h}$ of treatment (Figures $4 c$ and $d$ ). In order to evaluate the dynamics of LR induction, a time-course analysis of stained DR5:GUS roots was performed. Figure 4e shows statistically higher and faster induction of lateral root development by CS-MPs since CS-MPs treated seedlings 
showed an increased number of GUS-stained LR primordia compared with control after

$48 \mathrm{~h}$ and $72 \mathrm{~h}$ treatment. However, after $96 \mathrm{~h}$ no significant difference between treatments was found. This temporarily advance in auxin activation was also observed in PR where CS-MPs treated seedlings reached similar activation of DR5 promoter than control $48 \mathrm{~h}$ post-treatment (Figure $4 \mathrm{~b}$ ). The early and sustained activation of auxin response activity in DR5 reporter line fits with the promotion of root growth and development described in Figure 1.

a
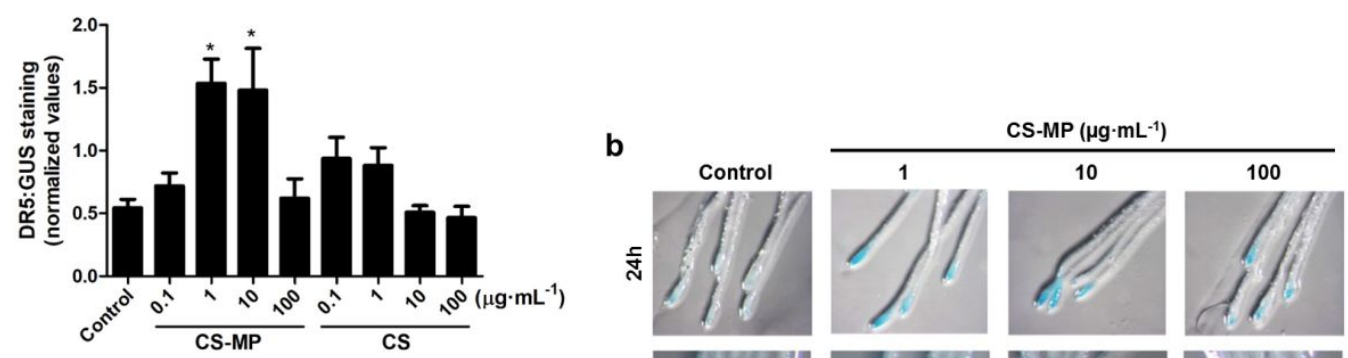

C
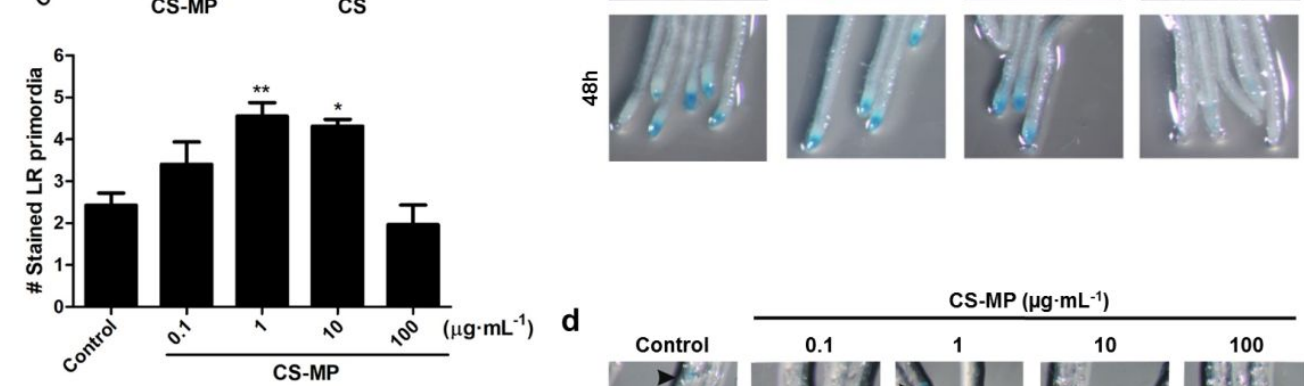

e
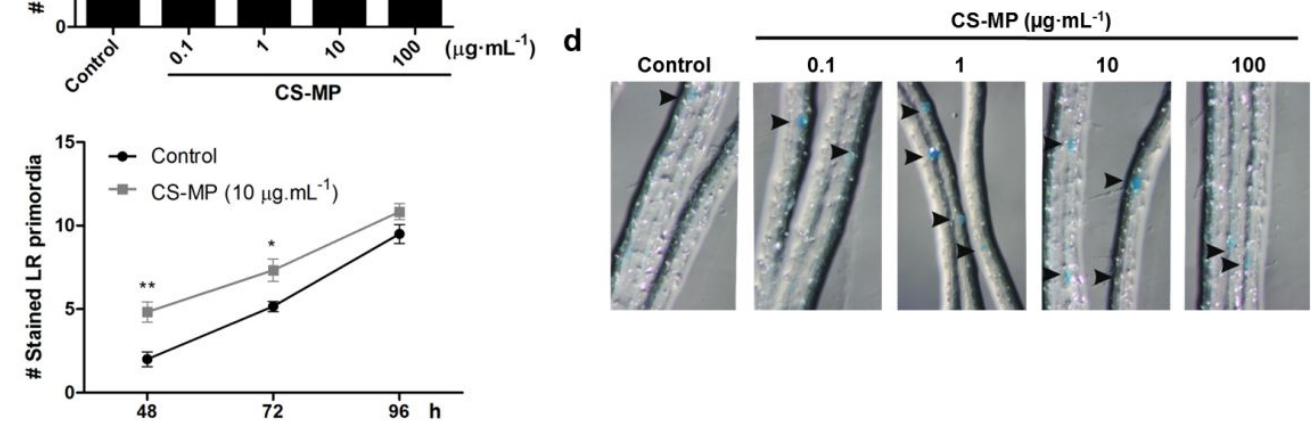

Figure 4. CS-MPs promote an early activation of auxin response in Arabidopsis roots. Five dpg DR5:GUS seedlings were transferred to liquid $1 / 2 \mathrm{MS}$ medium supplemented with increasing concentrations of MP-CS. GUS activity was revealed after incubation with X-Gluc at $37^{\circ} \mathrm{C}$. GUS activation in PR was analyzed $24 \mathrm{~h}$ posttreatment (a). GUS staining in representative root tip segments after $24 \mathrm{~h}$ and $48 \mathrm{~h}$ is representative root segments of the differentiation zone are shown in (d). Time-course analysis of stained primordia following 48,72 and $96 \mathrm{~h}$ of treatment with $10 \mu \mathrm{gL} \mathrm{mL}^{-1}$ is shown in (e) .Data are mean values of 5 independent experiments $(n=60$; ANOVA, Dunnet post-hoc test, ${ }^{*} p<0.05^{* *} p<0.01$ ). 


\section{CS-MPs trigger the activation of nuclear auxin signaling pathway}

To add evidence on the activation of the nuclear auxin signaling pathway, we analyzed the level of fluorescence emitted by the auxin sensor DII-VENUS in root cells from control and CS-MPs- treated plants. This auxin reporter line has been engineered to allow the detection of dynamic changes in the levels of Aux/IAA auxin repressor associated to a sensitive activation of nuclear TIR1/AFBs dependent auxin pathway. ${ }^{29}$ DII-VENUS sensor is rapidly degraded resulting in a decrease of the fluorescence when the auxin pathway is activated. A decrease in the DII-VENUS fluorescence signal was detected in the nucleus of epidermic cells in PR and LR of $10 \mu \mathrm{g} \mathrm{mL}^{-1}$ CS-MPstreated seedlings compared to control (Figures $5 a$ and b).

\section{a}

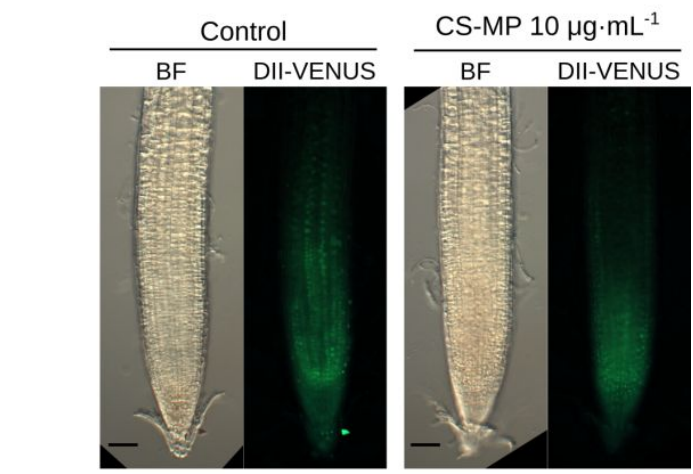

b

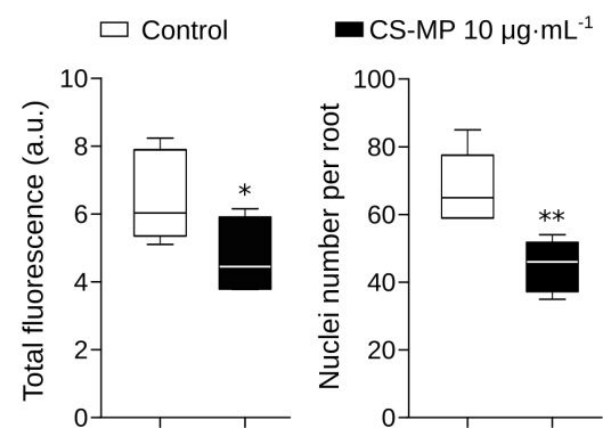

Figure 5. CS-MPs enhance auxin sensitive in DII-VENUS Arabidopsis seedlings. Five dpg DII-VENUS seedlings were transferred to liquid $1 / 2 \mathrm{MS}$ medium supplemented with $10 \mu \mathrm{g} \mathrm{mL}{ }^{-1}$ CS-MPs (a) DII-VENUS expression (green) in PR of control and CSMPs treated seedlings. Bright field images (BF). (b) Quantification of total DII-VENUS signal and DII-VENUS positive nuclei number per root. Box plot showing median, minimum and maximum values of 2 independent experiments $(n=24)$. P-values in 
337 comparison to control were calculated with two-tailed Student's t-test, ${ }^{*} p \leq 0.05{ }^{* *} p \leq$ 338 0.01. Scale bars, $50 \mu \mathrm{m}$.

339

340 Next, the expression of a set of auxin-response genes, Aux/IAAs (IAA5 and IAA14) and

$341 \mathrm{GH} 3 \mathrm{~s}$ (GH3.5 and GH3.17) was analyzed upon 1, 10 and $100 \mu \mathrm{gL}^{-1} \mathrm{CS}-\mathrm{MPs}$

342 treatment by quantitative qPCR (Figure 6). It is known that auxin response genes have

343 differential patterns of expression under auxin stimuli. ${ }^{37}$ Although each gene evidenced

344 a particular expression pattern, most of them were up-regulated in seedlings exposed

345 to 1 and $10 \mu \mathrm{g} \mathrm{mL}-1$ CS-MPs $24 \mathrm{~h}$ post treatment (Figures 6a-d). MSG2/IAA19

346 constitutes an early auxin response gene associated to root development.(26)

347 Therefore, the activation of IAA19 promoter in roots of $p M S G 2 / I A A 19: G U S$ reporter line

348 was analyzed in 1 and $10 \mu \mathrm{mL}^{-1}$ CS-MPs treated seedlings (Figure 6e). Both

349 concentrations of CS-MPs led to a significant increment of GUS staining in the PR

350 (Figure 6f). 
a

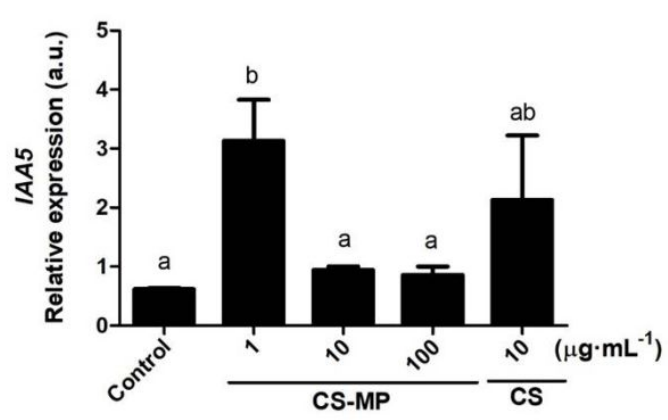

C

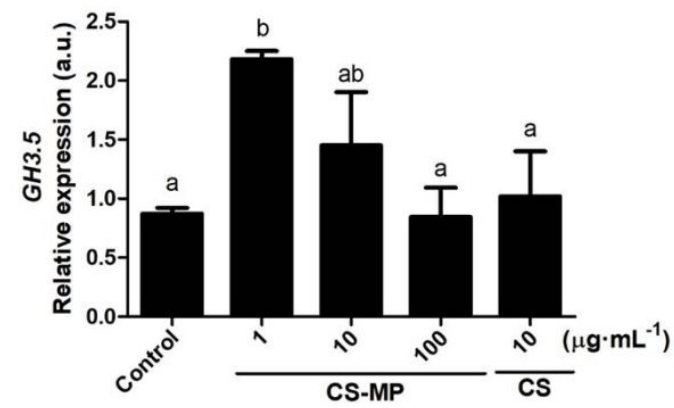

$\mathbf{e}$

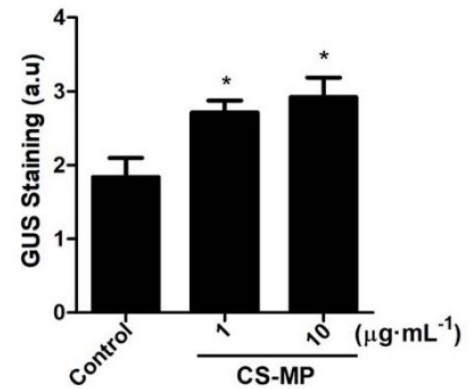

b

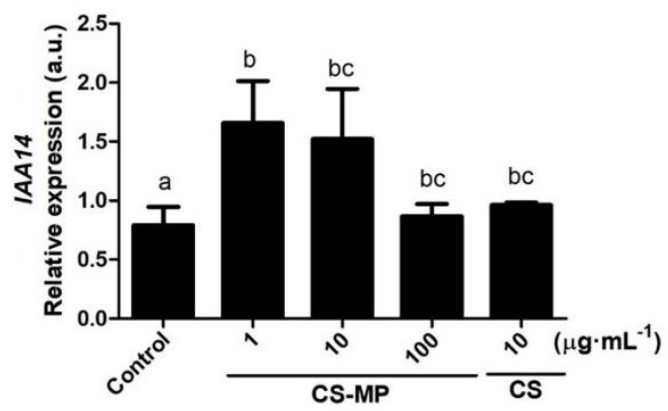

d

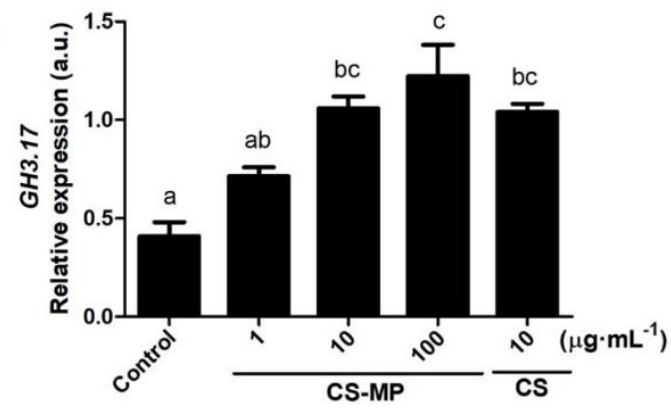

f

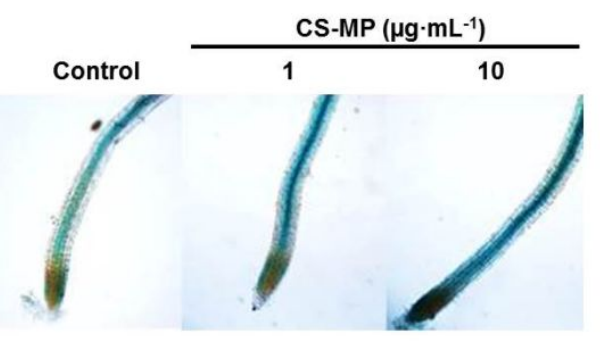

Figure 6. CS-MPs promote the activation of early auxin response genes in Arabidopsis seedlings. Five dpg Col- 0 seedlings were transferred to liquid $1 / 2 \mathrm{MS}$ medium supplemented with increasing concentrations of CS-MPs or CS as control. (ad) show the expression of a subset of early auxin response genes analyzed by qPCR after $24 \mathrm{~h}$ of CS-MPs treatment. (e) GUS activity in representative PR of $5 \mathrm{dpg}$ MSG2/IAA19:GUS Arabidopsis seedlings treated with 1 and $10 \mu \mathrm{gL} \mathrm{m}^{-1} \mathrm{CS}-\mathrm{MPs}$ for 24 h. Quantification of GUS staining in representative root tip segments is shown in (f). Data are mean values of 3 independent experiments $(n=30$; ANOVA, Dunnet post-hoc test against control, $\left.{ }^{*} p<0.05^{* *} p<0.01\right)$.

\section{DISCUSSION}

CS action seems to be complex in the dynamic and versatile modulation of plant developmental programs since a narrow change from optimal concentrations can lead from a promotion of growth to detrimental effects on plant biomass. ${ }^{12}$ CS-MPs 
modulate RAS inducing an early promotion of PR elongation, and a subsequent increment in the number and elongation of LRs and RHs compared to untreated seedlings root architecture in Arabidopsis and lettuce plants (Figures 1, 2 and S3). CSMPs exert its positive effect in a wide range of concentrations $\left(1-10 \mu \mathrm{gL}^{-1}\right)$, resulting in a very beneficial property to recommend doses of application in the field. This fact also represents improved properties compared to bulk CS and CS-nanoparticles recently described which inhibit root growth or alternatively induce root growth at specific doses showing cytotoxicity at higher concentration in several plant species including Arabidopsis thaliana, Solanum licopersicum, Hordeum vulgare, Capsicum annuum and Ipomoea purpurea treated with the same range of concentrations than in our study. 20,38,39 Main differences in our results could be attributed to physico-chemical properties of CS that become drastically changeable according to the biological sources and the synthesis methods. In our study CS exhibited a Mw of $1531 \pm 372 \mathrm{kDa}$ which is significantly higher than CS used in other published papers. $(20,38,39)$ Interestingly, the interaction between TPP- and -NH3+ groups of CS during the formation of the microstructure organization by the gelation method, confers new properties to the CS-MPs if compared to bulk CS macrostructure. CS present biological properties associated to its cationic nature under acidic $\mathrm{pH}$. The protonated amino groups of the glucosamine could interact by electrostatic interactions with anionic groups of the lipids of cell membrane, causing impairment on its physicochemical equilibrium. ${ }^{40}$ In CS-MP, these charged groups are partially neutralized and allow reorganization of the polymeric chains providing new properties to the CS-MP, which might have different interactions between the remaining free cationic groups and the cells. Assuming that the crosslinking efficiency is not $100 \%$ (TPP ratio was only $10 \%$ in the CS-MP), these remaining positively charge amino groups could interact with plasma membrane phospholipids as well as chelation of metal elements. ${ }^{11}$ Therefore, this new microstructure increases the surface of contact reducing the exposed $-\mathrm{NH} 3+$ positive charges of CS which could disrupt cell membrane potential. In addition, CS- 
MPs present a regular shape and medium size around $2.10 \mu \mathrm{m}$ which favors a better interaction with cells if compared with bulk CS. ${ }^{24}$ Then, the polymeric microstructure properties of CS-MPs make them an improved material for root growth promotion in a wider range of application doses compared with bulk CS. In addition, multiple evidences from genetic, molecular, and cellular approaches demonstrate the relevance of maintaining auxin gradients which ensure a proper activation of TIR1/AFBs- dependent auxin signaling during root development in Arabidopsis. ${ }^{15}$ It was recently reported that Arabidopsis seedlings react to sensible changes in auxin concentrations by extremely rapid adaptation of root growth rate. ${ }^{41}$ Therefore, compounds which exert an effect on auxin metabolism should be well characterized prior application. The fact that CS is able to induce a rapid and strong accumulation of auxin in Arabidopsis fits with the reports where plant growth is affected by it application. ${ }^{20}$ Although we used a CS of higher Mw than these authors, our results also demonstrated that CS triggers auxin signaling repression (Figure 3). However, CS-MPs unchain an accurate and coordinated spatio-temporal induction of the nuclear auxin signaling in CS-MPs-treated seedlings evidenced by the activation of DR5 promoter, the repression of DII-VENUS activity, and the expression of early auxin response genes, Aux/IAAs and $\mathrm{GH} 3$ s (Figures 4,5 and 6). A counter balance of nitric oxide (NO) concentrations appears to be essential for the control of the auxin action during root growth and development. ${ }^{42}$ The induction of NO levels by CS-MP (Figure S4) could contribute to the enhancement in auxin sensitivity which promotes root growth. NO exert its action, in part, through the S-nitrosylation of multiple components of the nuclear TIR1-dependent auxin signaling. ${ }^{43,44}$ Despite the differences in the dimensions of the particles with an average diameter of $90 \pm 5 \mathrm{~nm}$ compared to $2.10 \pm$ $0.78 \mu \mathrm{m}$ exhibited by the particles described in this work and in concordance with our 418 results, Chandra, et al. ${ }^{45}$ demonstrated that CS nanoparticles also induce NO 419 accumulation in addition to antioxidant enzymes as part of the defense response mechanism in Camellia sinensis tea plants suggesting that particles might mediate 
421 different physiological processes sharing, at least partially, the same signaling 422 mechanisms.

423 In addition, main differences in our results and previously reported papers could be 424 attributed to physicochemical properties of CS including the molecular weight since it 425 has been suggested that it has more influence on the biological activity than the DD. ${ }^{46}$ 426 The electrostatic interaction between TPP and -NH3+ groups of CS during the 427 formation of the MP allow to a new organization of the molecules of the polymer and 428 also a new way to exhibit the cationic charges reflected in the $\zeta$ of the CS-MP. This new conformation confers new properties to the material if compared to bulk CS macrostructure. This microstructure increases the surface of contact when compared to bulk CS reducing the exposed $-\mathrm{NH} 3+$ positive charges of $\mathrm{CS}$ which could disrupt cell membrane potential. ${ }^{24}$

Although auxin is considered an omnipotent regulator of root development cytokinin and jasmonate hormonal pathways and the crosstalk auxin-ethylene have been extensively described in the regulation of LR initiation, emergence and positioning in Arabidopsis. ${ }^{47,48}$ The fact that the application of CS-MPs to the double mutant in the auxin receptors TIR1 and AFB2, tir1afb2 was able to promote root FW and the number and length of LRs (Figure S5) suggests that CS-MPs enhance the sensitivity of remaining auxin receptors of TIR1/AFBs family or alternatively that CS-MPs exert its action through additional pathways.

Curiously, CS-MPs-induced phenotype resembles RSA of plants exposed to soil with low phosphate $(\mathrm{Pi})$ availability where modulation of auxin sensitivity leads to augmented density and length of LRs and RHs. ${ }^{49}$ However, CS-MPs enhanced root branching without a drastic effect on aerial organs in contrast to plants grown under low $\mathrm{Pi}$ which allocate more carbon to roots increasing their root-to-shoot ratio. ${ }^{50}$ Due to the relevance of soil $\mathrm{Pi}$ level for crop yield, Ham, et al. proposed the bio-engineering of agricultural species for improved $\mathrm{Pi}$ acquisition and utilization in plants. ${ }^{51}$ Although the 
mode of action of CS has not been completely deciphered yet, CS exhibits several reactive amino side groups which enhance its applicability. For instance, it has been demonstrated that CS stimulates the activity of plant symbiotic microbes affecting the homeostasis of microbial rhizosphere and also promoting the nutrient uptake by plant. ${ }^{52,53}$ Then, CS-MPs could participate in the modulation of Arabidopsis root interphase and/or the microbiome and associated mineral nutritional compounds. In this context, new CS biomaterials with improve biological performance like CS-MPs may constitute an overcome alternative to transgenic plants for the promotion of plant growth under soil with nutrient deficiency. However, further studies are necessary in order to decipher the cellular uptake and biodistribution of CS-MPs in root cells.

FUNDING

This work was supported by grants from ANPCyT (PICT start up0008, RAICES 0959), CONICET and Universidad Nacional de Mar del Plata and Gihon Laboratorios Químicos SRL, Mar del Plata Argentina.

ABBREVIATIONS

RSA, root system architecture; CS, chitosan; CS-MPs, chitosan microparticles; DPG, days post-germination; FW, fresh weight; IAA, Indole acetic acid; NO, nitric oxide; LR, lateral root; $\mathrm{PR}$, primary root; $\mathrm{RH}$, root hair; $\mathrm{SE}$, standard error; TPP, sodium tripolyphosphate;

SUPPORTING INFORMATION CONTENT

472 Figure S1. Characterization of CS-MP by SEM and FTIR.

Figure S2. Analysis of CS-MPs effect on root gravitropism in Arabidopsis.

Figure S3. Analysis of CS-MPs effect on root development in lettuce. 

roots. mutant.

1. Rogers, E. D.; Benfey, P. N., Regulation of plant root system architecture: implications for crop advancement. Current Opinion in Biotechnology 2015, 32, 93-98.

2. Meister, R.; Rajani, M.; Ruzicka, D.; Schachtman, D. P., Challenges of modifying root traits in crops for agriculture. Trends in Plant Science 2014, 19, 779-788.

3. Rogers, C.; Oldroyd, G. E., Synthetic biology approaches to engineering the nitrogen symbiosis in cereals. Journal of Experimental Botany 2014, 65, 1939-1946.

4. Anderson, J. A.; Gipmans, M.; Hurst, S.; Layton, R.; Nehra, N.; Pickett, J.; Shah, D. M.; Souza, T. L. P.; Tripathi, L., Emerging agricultural biotechnologies for sustainable agriculture and food security. Journal of agricultural and food chemistry 2016, 64, 383-393. 5. Tittonell, P., Ecological intensification of agriculture-sustainable by nature. Current Opinion in Environmental Sustainability 2014, 8, 53-61. 6. Pirbalouti, A. G.; Malekpoor, F.; Salimi, A.; Golparvar, A., Exogenous application of chitosan on biochemical and physiological characteristics, phenolic content and antioxidant activity of two species of basil (Ocimum ciliatum and Ocimum basilicum) under reduced irrigation. Scientia horticulturae 2017, 217, 114-122.

7. Malerba, M.; Cerana, R., Recent Advances of Chitosan Applications in Plants. Polymers 2018, 10, 118.

8. Yin, H.; Zhao, X.; Du, Y., Oligochitosan: a plant diseases vaccine-a review. Carbohydrate Polymers 2010, 82, 1-8. Evidence on antimicrobial properties and mode of action of a chitosan obtained from crustacean exoskeletons on Pseudomonas syringae pv. tomato DC3000. Applied microbiology and biotechnology 2013, 97, 6957-6966.

10.Iriti, M.; Varoni, E. M., Chitosan-induced antiviral activity and innate immunity in plants. Environmental Science and Pollution Research 2015, 22, 2935-2944.

11. Malerba, M.; Cerana, R., Chitosan effects on plant systems. International journal of molecular sciences 2016, 17, 996.

12.Pichyangkura, R.; Chadchawan, S., Biostimulant activity of chitosan in horticulture. Scientia Horticulturae 2015, 196, 49-65.

13.Vanneste, S.; Friml, J., Auxin: a trigger for change in plant development. Cell 2009, 136, 1005-1016.

14.Lavenus, J.; Goh, T.; Roberts, I.; Guyomarc'h, S.; Lucas, M.; De Smet, I.; Fukaki, H.; Beeckman, T.; Bennett, M.; Laplaze, L., Lateral root development in Arabidopsis: fifty shades of auxin. Trends in plant science 2013, 18, 450-458.

15.Overvoorde, P.; Fukaki, H.; Beeckman, T., Auxin control of root development. Cold Spring Harbor perspectives in biology 2010, a001537.

16.Chapman, E. J.; Estelle, M., Mechanism of auxin-regulated gene expression in plants. Annual review of genetics 2009, 43, 265-285. 
17.Hagen, G.; Guilfoyle, T., Auxin-responsive gene expression: genes, promoters and regulatory factors. Plant molecular biology 2002, 49, 373-385.

18. Khairullin, R.; Akhmetova, I.; Yusupova, Z., Inhibition of IAA-induced growth of wheat coleoptile fragments by chitin-chitosan oligomers. Biology Bulletin of the Russian Academy of 523 Sciences 2002, 29, 135-138. 19.Coqueiro, D. S. O.; de Souza, A. A.; Takita, M. A.; Rodrigues, C. M.; Kishi, L. T.; Machado, M. A., Transcriptional profile of sweet orange in response to chitosan and salicylic acid. $B M C$ genomics 2015, 16, 288.

20.Lopez-Moya, F.; Escudero, N.; Zavala-Gonzalez, E. A.; Esteve-Bruna, D.; Blázquez, M. A.; Alabadí, D.; Lopez-Llorca, L. V., Induction of auxin biosynthesis and WOX5 repression mediate changes in root development in Arabidopsis exposed to chitosan. Scientific reports 2017, 7, 16813.

21.Divya, K.; Smitha, V.; Jisha, M., Antifungal, antioxidant and cytotoxic activities of chitosan nanoparticles and its use as an edible coating on vegetables. International journal of biological macromolecules 2018, 114, 572-577.

22.Sreekumar, S.; Goycoolea, F. M.; Moerschbacher, B. M.; Rivera-Rodriguez, G. R., Parameters influencing the size of chitosan-TPP nano-and microparticles. Scientific reports 2018, 8, 4695.

23.Anitha, A.; Rani, V. D.; Krishna, R.; Sreeja, V.; Selvamurugan, N.; Nair, S.; Tamura, H.; Jayakumar, R., Synthesis, characterization, cytotoxicity and antibacterial studies of chitosan, Ocarboxymethyl and N, O-carboxymethyl chitosan nanoparticles. Carbohydrate Polymers 2009, 78, 672-677.

24.Martin-Saldaña, S.; Chevalier, M. T.; Iglesias, M. J.; Colman, S. L.; Casalongué, C. A.; Álvarez, V. A.; Chevalier, A. A., Salicylic acid loaded chitosan microparticles applied to lettuce seedlings: Recycling shrimp fishing industry waste. Carbohydrate Polymers 2018, 200, 321-331.

25.Zobel, R. W., Arabidopsis: An Adequate Model for Dicot Root Systems? Frontiers in plant science 2016, 7, 58.

26.Tatematsu, K.; Kumagai, S.; Muto, H.; Sato, A.; Watahiki, M. K.; Harper, R. M.; Liscum, E.; Yamamoto, K. T., MASSUGU2 encodes Aux/IAA19, an auxin-regulated protein that functions together with the transcriptional activator NPH4/ARF7 to regulate differential growth responses of hypocotyl and formation of lateral roots in Arabidopsis thaliana. The Plant Cell 2004, 16, 379-393.

27.UImasov, T.; Murfett, J.; Hagen, G.; Guilfoyle, T. J., Aux/IAA proteins repress expression of reporter genes containing natural and highly active synthetic auxin response elements. The Plant Cell 1997, 9, 1963-1971.

28.Oono, Y.; Chen, Q. G.; Overvoorde, P. J.; Köhler, C.; Theologis, A., age mutants of Arabidopsis exhibit altered auxin-regulated gene expression. The Plant Cell 1998, 10, 16491662.

29.Brunoud, G.; Wells, D. M.; Oliva, M.; Larrieu, A.; Mirabet, V.; Burrow, A. H.; Beeckman, T.; Kepinski, S.; Traas, J.; Bennett, M. J., A novel sensor to map auxin response and distribution at high spatio-temporal resolution. Nature 2012, 482, 103.

30.Duarte, M.; Ferreira, M.; Marvao, M.; Rocha, J., An optimised method to determine the degree of acetylation of chitin and chitosan by FTIR spectroscopy. International Journal of Biological Macromolecules 2002, 31, 1-8.

31.Cerchiara, T.; Abruzzo, A.; Di Cagno, M.; Bigucci, F.; Bauer-Brandl, A.; Parolin, C.; Vitali, B.; Gallucci, M.; Luppi, B., Chitosan based micro-and nanoparticles for colon-targeted delivery of vancomycin prepared by alternative processing methods. European Journal of Pharmaceutics and Biopharmaceutics 2015, 92, 112-119.

32.Jones, A. R.; Kramer, E. M.; Knox, K.; Swarup, R.; Bennett, M. J.; Lazarus, C. M.; Leyser, H. O.; Grierson, C. S., Auxin transport through non-hair cells sustains root-hair development. Nature cell biology 2009, 11, 78. 
569 33.Schindelin, J.; Arganda-Carreras, I.; Frise, E.; Kaynig, V.; Longair, M.; Pietzsch, T.; Preibisch, 570 S.; Rueden, C.; Saalfeld, S.; Schmid, B., Fiji: an open-source platform for biological-image 571 analysis. Nature methods 2012, 9, 676.

572 34.Pfaffl, M. W., A new mathematical model for relative quantification in real-time RT-PCR. 573 Nucleic acids research 2001, 29, e45-e45.

574 35.Shahidi, F.; Arachchi, J. K. V.; Jeon, Y.-J., Food applications of chitin and chitosans. Trends in 575 food science \& technology 1999, 10, 37-51.

576 36.París, R.; Vazquez, M. M.; Graziano, M.; Terrile, M. C.; Miller, N. D.; Spalding, E. P.; Otegui, 577 M. S.; Casalongué, C. A., Distribution of endogenous NO regulates early gravitropic response 578 and PIN2 localization in Arabidopsis roots. Frontiers in plant science 2018, 9, 495.

579 37.Goda, H.; Sawa, S.; Asami, T.; Fujioka, S.; Shimada, Y.; Yoshida, S., Comprehensive 580 comparison of auxin-regulated and brassinosteroid-regulated genes in Arabidopsis. Plant physiology 2004, 134, 1555-1573.

38.Acemi, A.; Bayrak, B.; Çakır, M.; Demiryürek, E.; Gün, E.; El Gueddari, N. E.; Özen, F., Comparative analysis of the effects of chitosan and common plant growth regulators on in vitro propagation of Ipomoea purpurea (L.) Roth from nodal explants. In Vitro Cellular \& Developmental Biology-Plant 2018, 54, 537-544.

39.Asgari-Targhi, G.; Iranbakhsh, A.; Ardebili, Z. O., Potential benefits and phytotoxicity of bulk and nano-chitosan on the growth, morphogenesis, physiology, and micropropagation of Capsicum annuum. Plant Physiology and Biochemistry 2018, 127, 393-402.

40.Elgadir, M. A.; Uddin, M. S.; Ferdosh, S.; Adam, A.; Chowdhury, A. J. K.; Sarker, M. Z. I., Impact of chitosan composites and chitosan nanoparticle composites on various drug delivery systems: A review. Journal of food and drug analysis 2015, 23, 619-629.

41.Fendrych, M.; Akhmanova, M.; Merrin, J.; Glanc, M.; Hagihara, S.; Takahashi, K.; Uchida, N.; Torii, K. U.; Friml, J., Rapid and reversible root growth inhibition by TIR1 auxin signalling. Nature Plants 2018, 4, 453.

42.Correa-Aragunde, N.; Foresi, N.; Lamattina, L., Auxin and nitric oxide: a counterbalanced partnership ensures the redox cue control required for determining root growth pattern. In Advances in Botanical Research, Elsevier: 2016; Vol. 77, pp 41-54.

43.Terrile, M. C.; París, R.; Calderón-Villalobos, L. I.; Iglesias, M. J.; Lamattina, L.; Estelle, M.; Casalongué, C. A., Nitric oxide influences auxin signaling through S-nitrosylation of the Arabidopsis TRANSPORT INHIBITOR RESPONSE 1 auxin receptor. The Plant Journal 2012, 70, 492-500.

44.Iglesias, M. J.; Terrile, M. C.; Correa-Aragunde, N.; Colman, S. L.; Izquierdo-Álvarez, A.; Fiol, D. F.; París, R.; Sánchez-López, N.; Marina, A.; Calderón Villalobos, L. I. A.; Estelle, M.; Lamattina, L.; Martínez-Ruiz, A.; Casalongué, C. A., Regulation of SCFTIR1/AFBs E3 ligase assembly by S-nitrosylation of Arabidopsis SKP1-like1 impacts on auxin signaling. Redox Biology 2018, 18, 200-210.

45.Chandra, S.; Chakraborty, N.; Dasgupta, A.; Sarkar, J.; Panda, K.; Acharya, K., Chitosan nanoparticles: a positive modulator of innate immune responses in plants. Scientific reports 2015, 5, 15195.

46.Goy, R. C.; Britto, D. d.; Assis, O. B., A review of the antimicrobial activity of chitosan. Polímeros 2009, 19, 241-247.

47.Olatunji, D.; Geelen, D.; Verstraeten, I., Control of endogenous auxin levels in plant root development. International journal of molecular sciences 2017, 18, 2587.

48.Liu, J.; Moore, S.; Chen, C.; Lindsey, K., Crosstalk complexities between auxin, cytokinin and ethylene in Arabidopsis root development: from experiments to systems modelling, and back again. Molecular plant 2017.

49.Pérez-Torres, C.-A.; López-Bucio, J.; Cruz-Ramírez, A.; Ibarra-Laclette, E.; Dharmasiri, S.; Estelle, M.; Herrera-Estrella, L., Phosphate availability alters lateral root development in Arabidopsis by modulating auxin sensitivity via a mechanism involving the TIR1 auxin receptor. The Plant Cell 2008, 20, 3258-3272. 
621 50.Hermans, C.; Hammond, J. P.; White, P. J.; Verbruggen, N., How do plants respond to 622 nutrient shortage by biomass allocation? Trends in plant science 2006, 11, 610-617.

623 51.Ham, B.-K.; Chen, J.; Yan, Y.; Lucas, W. J., Insights into plant phosphate sensing and 624 signaling. Current opinion in biotechnology 2018, 49, 1-9.

625 52.Sharif, R.; Mujtaba, M.; Ur Rahman, M.; Shalmani, A.; Ahmad, H.; Anwar, T.; Tianchan, D.; 626 Wang, X., The multifunctional role of chitosan in horticultural crops; a review. Molecules 2018, $62723,872$.

628 53.Agbodjato, N. A.; Noumavo, P. A.; Adjanohoun, A.; Agbessi, L.; Baba-Moussa, L., Synergistic 629 effects of plant growth promoting rhizobacteria and chitosan on in vitro seeds germination, 630 greenhouse growth, and nutrient uptake of maize (Zea mays L.). Biotechnology research 631 international 2016, 2016, 1-11.

632

633 


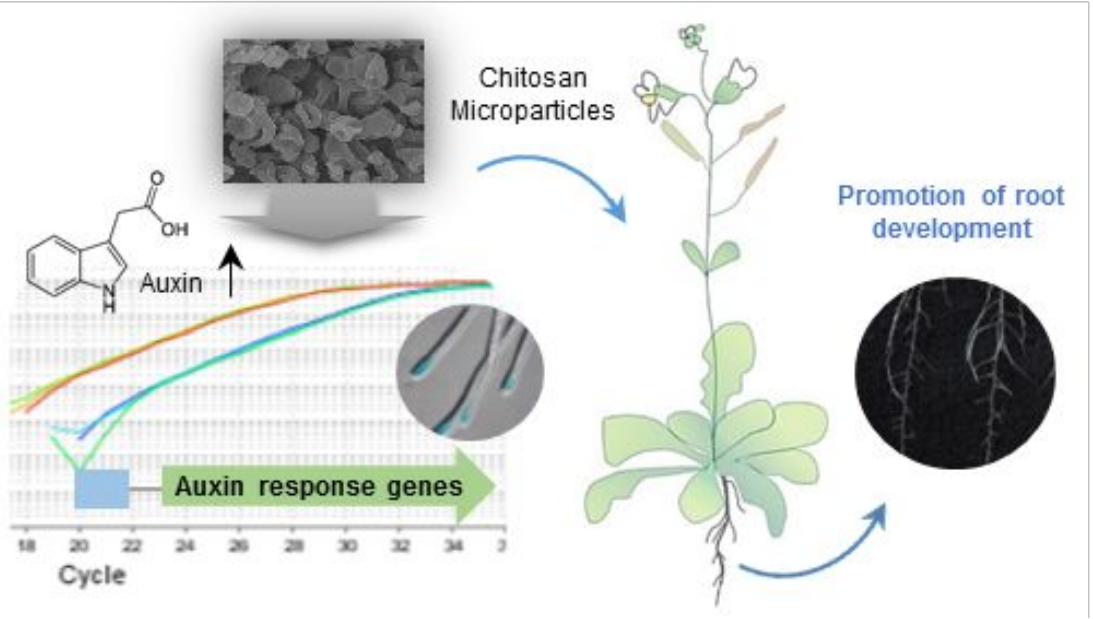

635 
a

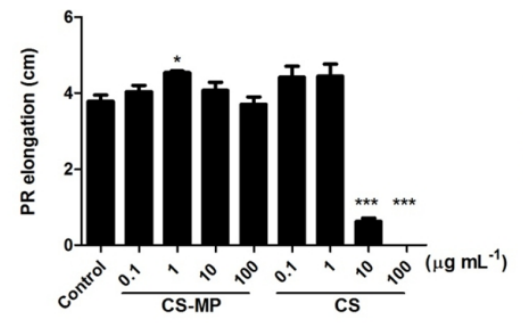

C

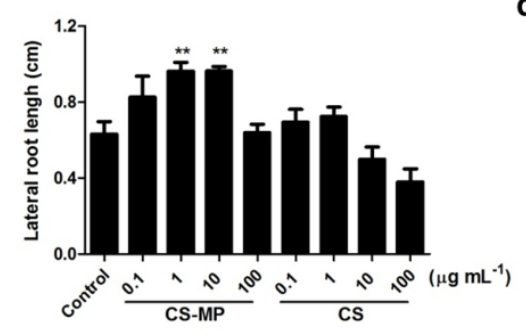

b

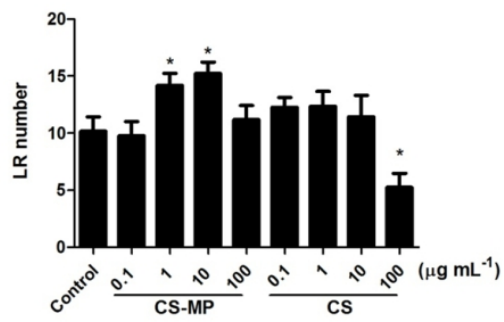

d

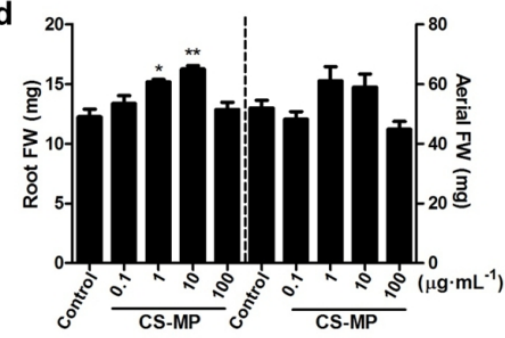

e

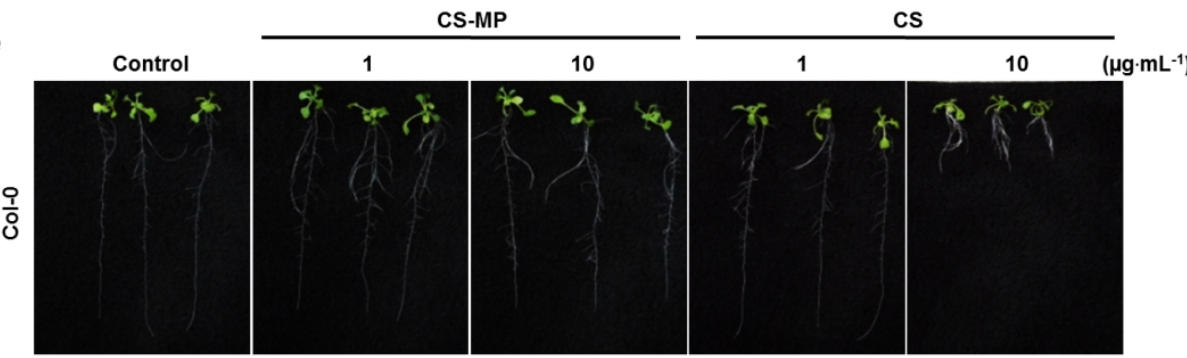

Figure 1. CS-MPs promote root development in Arabidopsis. Five dpg Col-0 Arabidopsis seedlings grown in $1 / 2$ MS medium were treated with increasing concentrations of CS-MPs or CS as control. PR elongation (a) was quantified $3 \mathrm{~d}$ post- treatment. LR number (b) and LR length (c) were analyzed $5 \mathrm{~d}$ post treatment. Seedlings FW was quantified $9 \mathrm{~d}$ post- treatment (d). Representative images $9 \mathrm{~d}$ post treatments are shown in (e). Data are mean values of 5 independent experiments $(n=60 ;$ ANOVA, Dunnet post-hoc test against control, $* \mathrm{p}<0.05 * * \mathrm{p}<0.01 * * * \mathrm{p}<0.001)$.

$252 \times 236 \mathrm{~mm}(150 \times 150 \mathrm{DPI})$ 
a

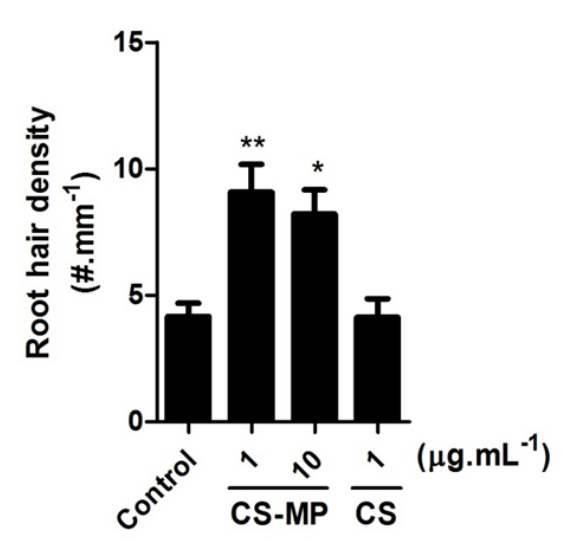

b

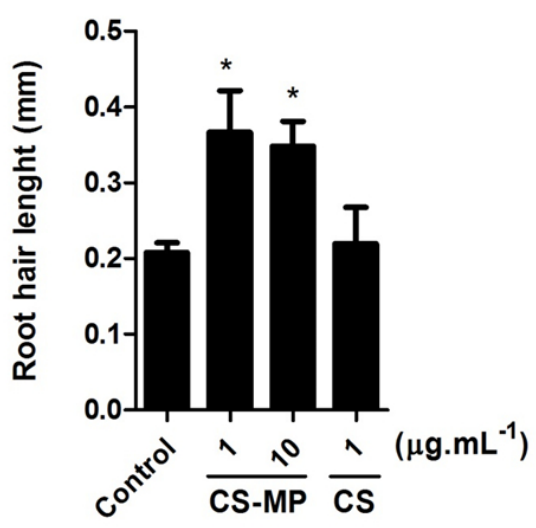

C

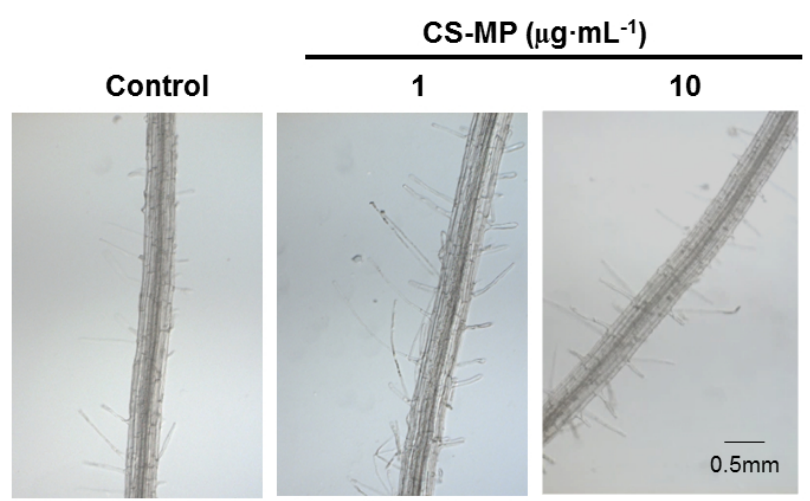

Figure 2. Promotion of RH upon CS-MPs exposure. Five dpg Col-0 Arabidopsis seedlings were transferred to liquid $1 / 2$ MS medium supplemented with increasing concentrations of CS-MPS for $48 \mathrm{~h}$. RH density (a) and

$\mathrm{RH}$ length (b) were analyzed in a $5 \mathrm{~mm}$ section from the beginning of the differentiation zone.

Representative images are shown in (c). Data are mean values of 4 independent experiments $(n=30$; ANOVA, Dunnet post-hoc test against control, * $p<0.05$ ).

$186 \times 173 \mathrm{~mm}(150 \times 150 \mathrm{DPI})$ 


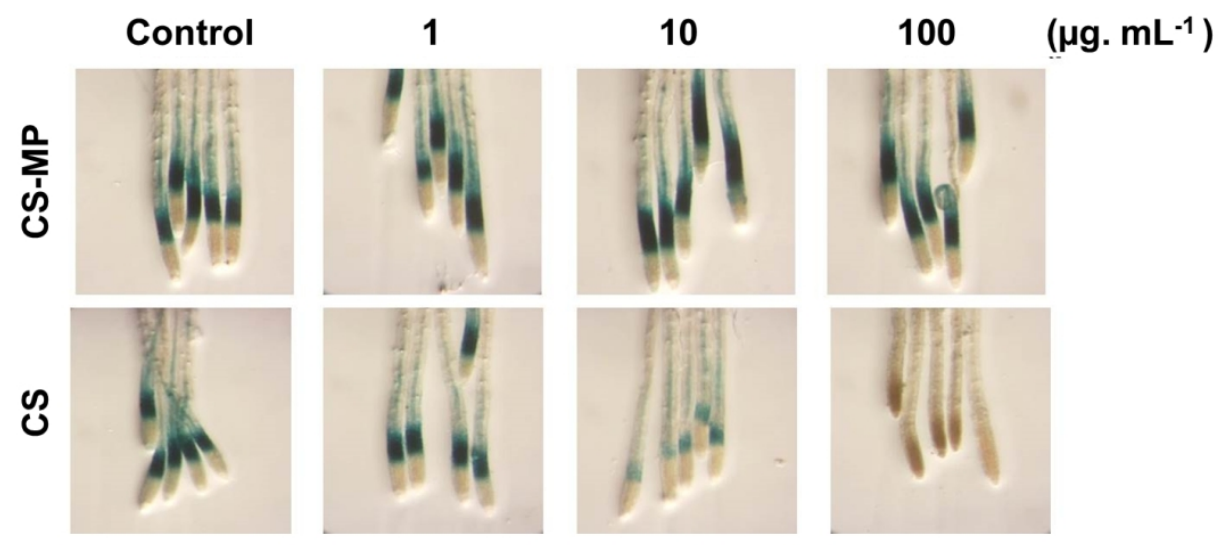

Figure 3. Differential effect of CS-MPs and CS on auxin BA3:GUS reporter gene activity. Five dpg Arabidopsis BA3:GUS seedlings grown in $1 / 2$ MS medium were treated with $100 \mathrm{nM}$ IAA and increasing concentrations of CS-MPS or CS. Seedlings were subjected to GUS staining after $5 \mathrm{~h}$ of treatment. Representative images of PR tips are shown.

$255 \times 120 \mathrm{~mm}(150 \times 150 \mathrm{DPI})$ 
a

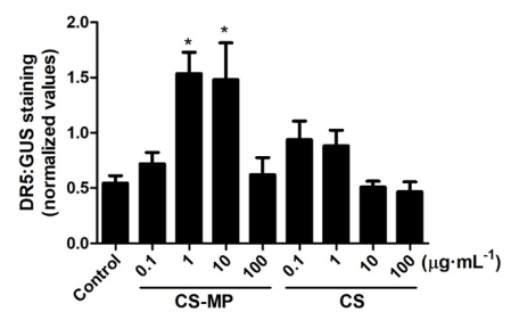

c
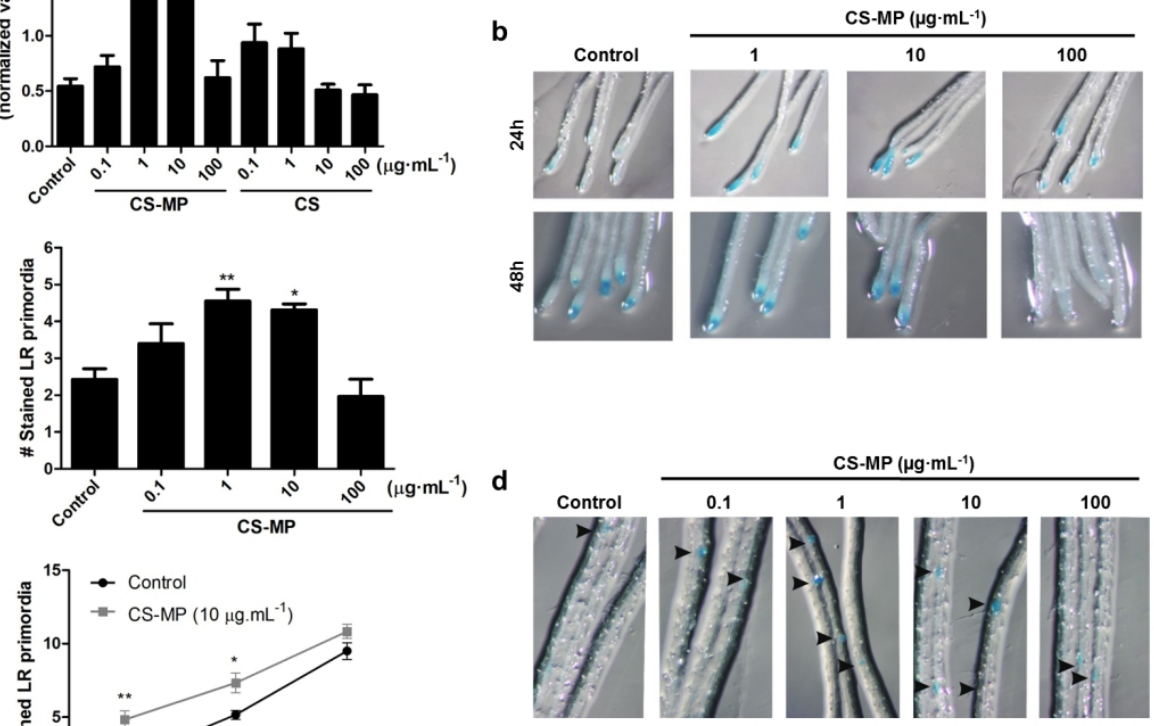

e

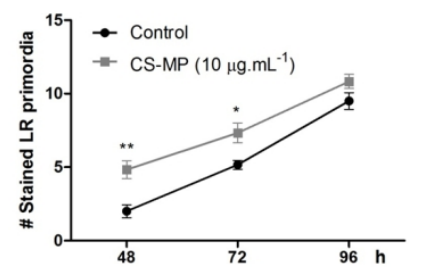

Figure 4. CS-MPs promote an early activation of auxin response in Arabidopsis roots. Five dpg DR5:GUS seedlings were transferred to liquid $1 / 2$ MS medium supplemented with increasing concentrations of MP-CS. GUS activity was revealed after incubation with X-Gluc at $37^{\circ} \mathrm{C}$. GUS activation in PR was analyzed $24 \mathrm{~h}$ post-treatment (a). GUS staining in representative root tip segments after $24 \mathrm{~h}$ and $48 \mathrm{~h}$ is shown in b. Stained LR primordia were quantified after $48 \mathrm{~h}$ (c). GUS staining in representative root segments of the differentiation zone are shown in (d). Time-course analysis of stained primordia following 48,72 and $96 \mathrm{~h}$ of treatment with $10 \mu \mathrm{g} \mathrm{mL}-1$ is shown in (e). Data are mean values of 5 independent experiments $(n=60$; ANOVA, Dunnet post-hoc test, $\left.{ }^{*} \mathrm{p}<0.05 * * \mathrm{p}<0.01\right)$.

$297 \times 224 \mathrm{~mm}(150 \times 150 \mathrm{DPI})$ 
a
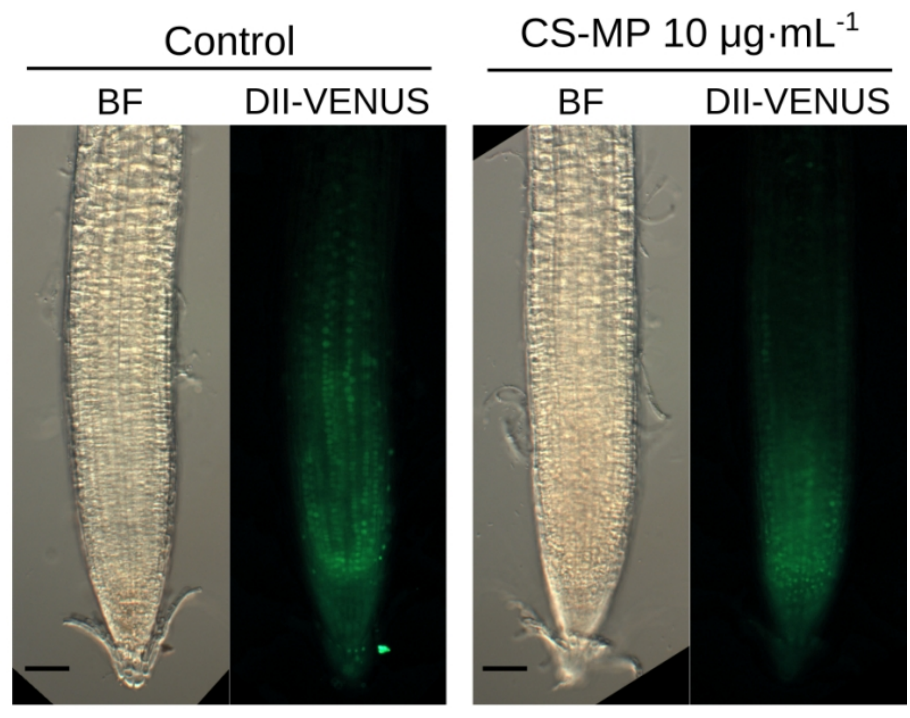

b

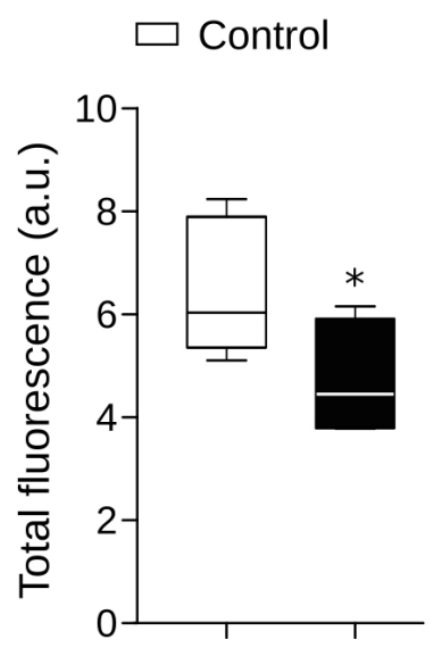

- CS-MP $10 \mu \mathrm{g} \cdot \mathrm{mL}^{-1}$

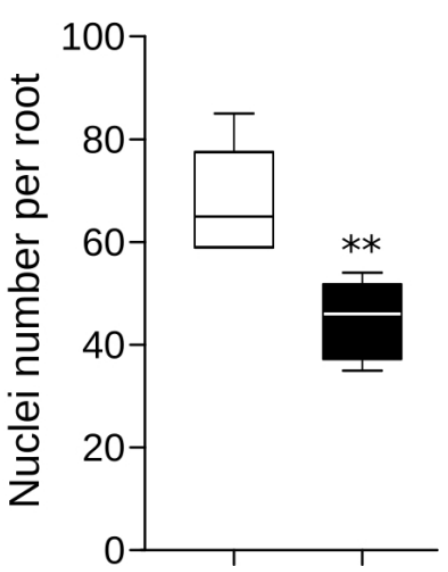

Figure 5. CS-MPs enhance auxin sensitive in DII-VENUS Arabidopsis seedlings. Five dpg DII-VENUS seedlings were transferred to liquid $1 / 2$ MS medium supplemented with $10 \mu \mathrm{g} \mathrm{mL-1} \mathrm{CS-MPS} \mathrm{(a)} \mathrm{DII-VENUS}$ expression (green) in PR of control and CS-MPs treated seedlings. Bright field images (BF). (b)

Quantification of total DII-VENUS signal and DII-VENUS positive nuclei number per root. Box plot showing median, minimum and maximum values of 2 independent experiments $(n=24)$. P-values in comparison to control were calculated with two-tailed Student's t-test, $* p \leq 0.05 * * p \leq 0.01$. Scale bars, $50 \mu \mathrm{m}$.

$372 \times 561 \mathrm{~mm}(72 \times 72 \mathrm{DPI})$ 


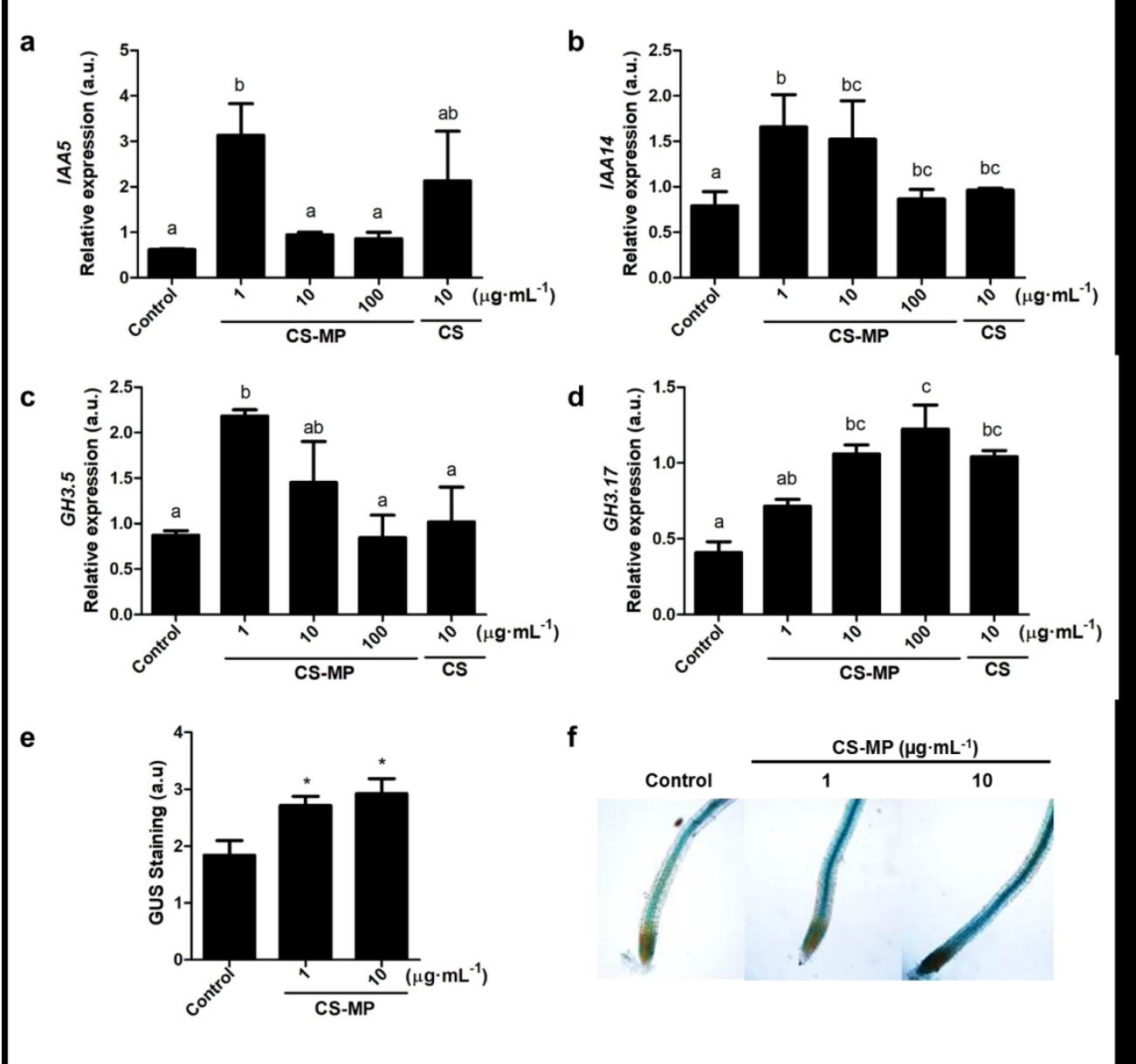

Figure 6. CS-MPs promote the activation of early auxin response genes in Arabidopsis seedlings. Five dpg Col-0 seedlings were transferred to liquid $1 / 2$ MS medium supplemented with increasing concentrations of CSMPs or CS as control. (a-d) show the expression of a subset of early auxin response genes analyzed by qPCR after $24 \mathrm{~h}$ of CS-MPs treatment. (e) GUS activity in representative PR of $5 \mathrm{dpg}$ MSG2/IAA19:GUS

Arabidopsis seedlings treated with 1 and $10 \mu \mathrm{g} \mathrm{mL-1} \mathrm{CS-MPs} \mathrm{for} 24 \mathrm{~h}$. Quantification of GUS staining in representative root tip segments is shown in (f). Data are mean values of 3 independent experiments $(n=$ 30; ANOVA, Dunnet post-hoc test against control, $* p<0.05 * * p<0.01)$. 


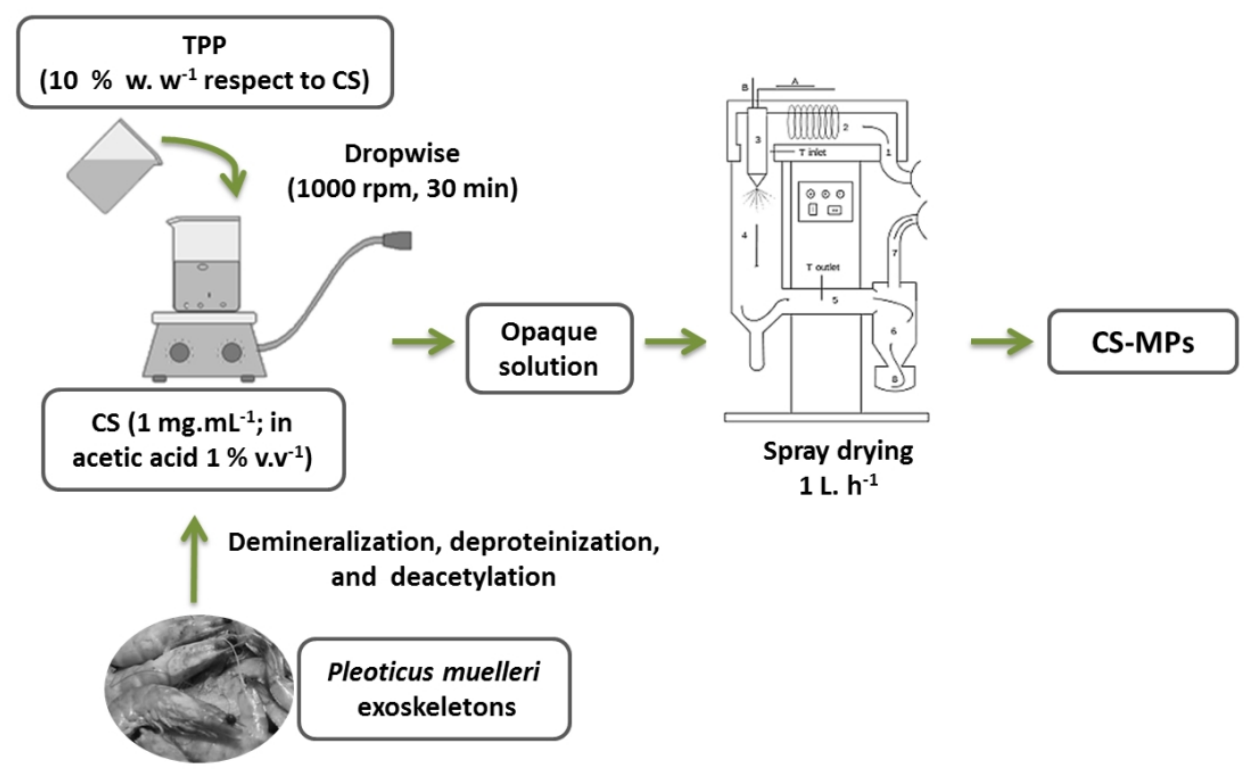

Scheme 1: Synthesis of CS-MPs

$219 \times 137 \mathrm{~mm}(150 \times 150 \mathrm{DPI})$ 